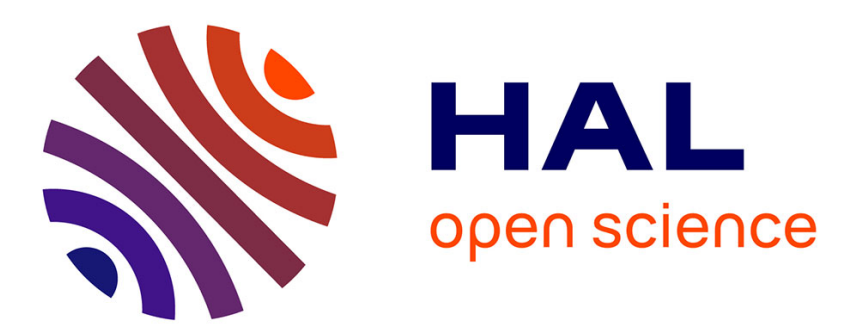

\title{
Natural and synthetic poly(malic acid)-based derivates: A family of versatile biopolymers for the design of drug nanocarriers.
}

\author{
Pascal Loyer, Sandrine Cammas-Marion
}

\section{- To cite this version:}

Pascal Loyer, Sandrine Cammas-Marion. Natural and synthetic poly(malic acid)-based derivates: A family of versatile biopolymers for the design of drug nanocarriers.. Journal of Drug Targeting, 2014, 22 (7), pp.556. 10.3109/1061186X.2014.936871 . hal-01063205

HAL Id: hal-01063205

https://hal-univ-rennes1.archives-ouvertes.fr/hal-01063205

Submitted on 12 Sep 2014

HAL is a multi-disciplinary open access archive for the deposit and dissemination of scientific research documents, whether they are published or not. The documents may come from teaching and research institutions in France or abroad, or from public or private research centers.
L'archive ouverte pluridisciplinaire $\mathbf{H A L}$, est destinée au dépôt et à la diffusion de documents scientifiques de niveau recherche, publiés ou non, émanant des établissements d'enseignement et de recherche français ou étrangers, des laboratoires publics ou privés. 
Natural and synthetic poly(malic acid)-based derivates: A family of versatile biopolymers for the design of drug nanocarriers.

Pascal Loyer ${ }^{1}$, Sandrine Cammas-Marion ${ }^{2, *}$

1. Inserm UMR S-991; Foie, Métabolismes et Cancer; Université de Rennes 1; Fédération de Recherche Biosit; CHU Rennes; 35033 Rennes, France.

2. UMR 6226 CNRS; Institut des Sciences Chimiques de Rennes; Université de Rennes 1; Ecole Nationale Supérieure de Chimie de Rennes; Avenue du Général Leclerc; CS 50837; 35708 Rennes Cedex, France.

*Corresponding author:

Tel: +33223238109

Mail: sandrine.marion.1@ensc-rennes.fr

In memory of Professor Philippe Guérin

Keywords: degradable polymers, drug delivery systems, drug-polymer conjugates, nanoparticles, poly(malic acid), targeting. 


\begin{abstract}
The field of specific drug delivery is an expanding research domain. Besides the use of liposomes formed from various lipids, natural and synthetic polymers have been developed to prepare more efficient drug delivery systems either under macromolecular prodrugs or under particulate nanovectors. To ameliorate the biocompatibility of such nanocarriers, degradable natural or synthetic polymers have attracted the interest of many researchers. In this context, poly(malic acid) (PMLA) extracted from microorganisms or synthesized from malic or aspartic acid was used to prepare water-soluble drug carriers or nanoparticles. Within this review, both the preparation and the applications of PMLA derivatives are described emphasizing the in vitro and in vivo assays. The results obtained by several groups highlight the interest of such polyesters in the field of drug delivery.
\end{abstract}

\title{
Introduction
}

Since the term Magic Bullet was coined by Paul Ehrlich nearly a century ago [1], the concept of efficient drug delivery systems for therapy in Humans is becoming a reality. Indeed, owing to the quest for more effective treatments of several diseases such as cancers, numerous researches have been and continue to be performed on the development of systems able to deliver high amount of drugs at a specific site of action while decreasing non-specific distribution and toxicity. As a consequence of such considerable research works, some of the developed nanovectors, especially liposome and nanoparticles, have already received FDA approval or are in the preclinical or clinical phases [2-6]. However, even if undeniable progresses have been achieved in the design of the ideal drug carriers, several properties, such as the biocompatibility, drug loading capacity, and site-specificity of drug delivery as well as a reduced immunogenicity of the carrier following its administration in the body need further improvement.

Among drug delivery systems designed to address these objectives, polymer based carriers have attracted much interest mainly because of the versatile characteristics of polymers allowing adjustment of the physico-chemical and biological properties of the corresponding nanocarriers. Consequently, several families of polymers have been developed to formulate multifunctional drug carriers with properties adjusted to the considered application [7]. However, when designing a polymer family, one must keep in mind that the resulting materials are prepared to be used in vivo. Therefore, it is necessary to develop polymers corresponding to very strict specifications among which the following ones are of 
great importance: (i). biocompatibility at any stage of the material life and until its complete excretion from the body, (ii). the lack of toxicity, (iii). the stealth and reduced immunogenicity, (iv). ability to carry large amount of drug(s), (v). the drug delivery at a specific site in a sustainable way.

Besides these essential properties, the (bio)degradability of the polymers constituting the drug delivery systems can be of interest in the sense that the carrier can be eliminated from the body as a result of its (bio)degradability. However, this means that the degradation process must lead to non-immunogenic, biocompatible and/or (bio)assimilable low molecular weight molecules that can be eliminated through bile and/or urine.

In the field of drug delivery systems, several stable or (bio)degradable polymers have been developed and formulated under either macromolecular linear prodrugs or nanoparticulate forms [7-10].

As described by Ringsdorf in 1975, a macromolecular linear prodrug, called also polymer-drug conjugate, is constituted by a (bio)degradable or biostable polymer backbone on which several functionalities are introduced: (i). water or lipid solubilizer as comonomer units or blocks, (ii). biologically active molecules linked to the backbone through a degradable bound, (iii). targeting agents and body distribution modulator groups [11]. Since the Ringsdorf's model, several systems have been developed [3]. Recently, Pang et al. have published a review on the present state and future perspectives of polymer-drug conjugates: the most studied polymer-drug conjugates were described in terms of structures and nature of the conjugated drug as well as the possible applications and the ongoing clinical trials if any, etc. [12]. However, even if such carriers have been widely investigated, further improvements are required to minimize the material's heterogeneity by optimizing the synthesis, to find versatile linkers for site-specific controlled release and to decrease the immunogenicity of the polymer-drug conjugates.

Besides such linear drug delivery systems, nanoparticulate carriers have emerged following the pioneer works realized by Professor Kataoka's team on macromolecular micelles based on amphiphilic block copolymers of hydrophilic poly(ethylene glycol), PEG, and hydrophobic poly(amino acids) blocks [13]. In the meantime, Kabanov's group developed nanoparticulate carriers via the work performed on Pluronic ${ }^{\circledR}$ micelles [14].

In this context, the design of (bio)degradable polymers, whose physico-chemical and biological properties can be adjusted either by copolymerization, chemical modifications or both, are of great importance [15,16]. Poly(malic acid) (PMLA) (Figure 1) is a very good candidate due to the presence of carboxylic acid pendant groups, which can be chemically 
modified to introduce molecules of interest, and ester cleavable bounds within the polymer backbone, allowing the degradation of the polymer main chain into biocompatible metabolites [17].

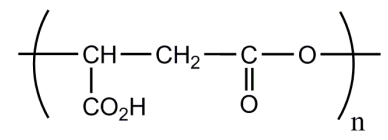

$\operatorname{Poly}(\beta-$ malic acid $)$

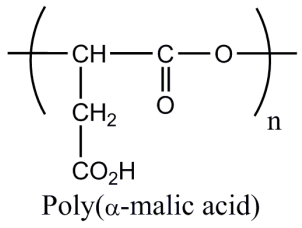

$\operatorname{Poly}(\alpha-$ malic acid $)$

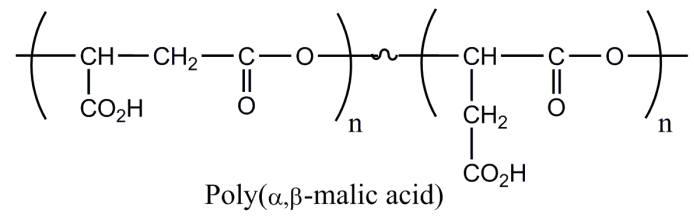

Figure 1. Structure of the different forms of poly(malic acid).

Moreover, following the synthesis of a large monomer family of malolactonates (MLAR) and their homo- and/or co-polymerization, numerous PMLA derivatives are now accessible with physico-chemical and biological properties depending on the nature of the repeating units forming the polymer [18-20]. Besides these synthetic macromolecular materials, natural poly(malic acid) can be obtained from the plasmodia extracts and from the culture medium of Physarum polycephalum [21]. The adjustment of physico-chemical and biological properties of the natural PMLA can be realized only by chemical modifications of the naturally available polyester.

In this article, we present an overview on the researches conducted on both natural and synthetic PMLA derivatives for designing multifunctional drug carriers under forms of either drug-polymer conjugates or nanoparticles. In a first part, preparation and characterization of natural PMLA derivatives will emphasize the in vitro/in vivo assays. The second part will focus on both the synthesis of the PMLA's derivatives and the applications of such synthetic polymers as drug carriers.

\section{Drug delivery systems based on natural PMLA}

At the end of the 1980s, Holler et al. have isolated an unusual polyanion from plasmodium extracts and from the culture medium of $P$. polycephalum [21]. They have shown that this polyanion inhibits the DNA polymerase $\alpha$ of this organism and that it exhibited a poly(malate) 
structure [21]. Few years later, we demonstrated that this natural PMLA compound is the $\beta$ ester form of the poly( $\beta$-malic acid) obtained by chemical synthesis [22]. The natural polyester has attracted the attention of researchers as a result of its potential application in the drug delivery system field. The natural PMLA has been indeed used, either unaltered or following chemical modifications (Figure 2) to formulate nanoparticles [23-28] or as nanoplatforms called Polycefins ${ }^{\mathrm{TM}}[29-50]$.

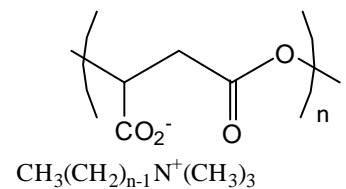

Ionic complexes

Erythromycin encapsulation [22,25]<smiles>CC(C)(C)OC(=O)CC(CC(=O)OC(C)(C)C)OC(=O)O</smiles>

R: methyl, L-leucine ethyl ester or L-phenyl alanine methyl ester Nano and microparticles Nanoplatforms

Encapsulation of protein, antibiotic or anti-cancer drugs In vitro assays $[23,24,26,27,49]$

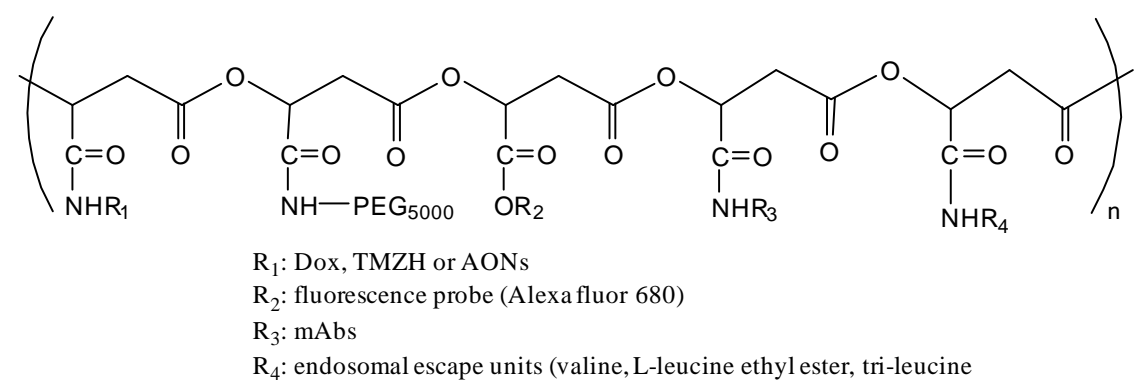

Polycephin ${ }^{\mathrm{TM}}$ nanoplatforms

Studies of cytotoxicity in vitro, interactions with membranes, mechanism of membrane permeation Vectorization of Dox, TMZH or AONs

In vitro and in vivo assays [28-48]

Figure 2. Structures and characteristics of Nat-PMLA derivatives.

\section{Nanoparticles based on natural PMLA}

Muñoz-Guerra et al. have developed derivatives of natural PMLA with the goal of elaborating ionic complexes as well as nano- and micro-particles for drug delivery [23-28]. Ionic complexes were obtained by mixing aqueous solutions of natural PMLA and alkyltrimethylammonium sulfates $[23,26]$.

The degradation of such complexes occurred by hydrolysis with a rate that can be modulated by changing the chemical structure of either the main chain or the surfactant alkyl chain $[23,26]$. Moreover, up to $30 \mathrm{wt} \%$ of the drug erythromycin can be homogenously entrapped within the ionic matrix and the kinetics of release followed the hydrolysis profile 
regardless of the loaded amounts [23,26]. Despites these interesting observations, to the best of our knowledge no result of cell based assays have been reported using these biomaterials.

Besides this work, Muñoz-Guerra et al. have also synthesized derivatives of natural PMLA containing hydrophobic groups and prepared the corresponding nano- and microparticles [24,25,27,28]. These derivatives have been obtained by reacting diazomethane [24,27,28] or by grafting hydrophobic amino acids [25] on natural PMLA.

Two hydrophobic amino acids have been grafted onto natural PMLA, the L-leucine ethyl ester and the L-phenyl alanine methyl ester, in proportions of 30\%, 60\% and 90\% without dramatically affecting the molecular weights and polymolecularities of the obtained derivatives [25]. Nanoparticles have been prepared from natural PMLA containing 60\% of amino acid (L-leucine ethyl ester or L-phenyl alanine methyl ester) using the precipitationdialysis method. Spherical nanoparticles with a diameter ranging from 70 to $230 \mathrm{~nm}$ were obtained [25] and cytotoxicity assays realized with two kinds of nanoparticles on various cancer cell lines have evidenced a concentration-dependent cytotoxicity but only for polymer concentrations above $125 \mu \mathrm{g} / \mathrm{ml}$. Muñoz-Guerra et al. concluded that such dose-dependent cytotoxicity was related to the binding of polymer to cell membranes leading to irreversible membrane dys-organization [25]. However, they did not report any experiment evidencing such nanoparticles-cell membrane interactions. Finally, they evaluated the use of such nanoparticles as drug carriers by studying loading and release with two drugs, Temozolomide (TMZ) and Doxorubicin (Dox) [25]. The drug encapsulation was quite low with a fast release for TMZ and a slower release for Dox [25]. Unfortunately, no cell cytotoxicity assays and in vitro drug delivery of the drug carriers have been conducted.

Muñoz-Guerra et al. mainly studied the synthesis, characterization and formulation of methyl ester of natural PMLA [24,27,28]. Beginning from either $75 \%$ or $100 \%$ methylated natural PMLA, they formulated nano- or micro-particles, by precipitation-dialysis or emulsion-evaporation methods with the goal to use these systems as proteins or drugs carriers. The micro-sphere diameters were in the range of 1 to $20 \mu \mathrm{m}$ [28] while the size of nanoparticles formulated with the same polymers varied from 100 to $350 \mathrm{~nm}$ [24,27]. Several proteins [27], an antibiotic molecule [28] and two anti-cancers drugs [24] have been used to evaluate the potential of these biodegradable nano- and micro-particles as drug carriers. The encapsulation efficiency was shown to be dependent on the nature of the loaded molecule while the kinetics of drug release seem to be determined by polymer degradation rate $[24,27,28]$. Finally, cytotoxicity assays using various cancer cell lines have been realized with nanoparticles formulated with fully methylated natural PMLA. After one hour of incubation 
with nanoparticles at a polymer concentration up to $1 \mathrm{mg} / \mathrm{ml}$, the cell viability was not affected; however, it decreased significantly after 12 hours of incubation at all the polymer concentrations tested. Muñoz-Guerra et al. estimated that such toxicity came from the methanol released during polymer degradation [24].

Such research has highlighted the key role of the nature of the ester side groups which not only allows the adjustment of physico-chemical properties of the biopolymer but also affects its biocompatibility and its interactions with the biological environment.

\section{Nanoplatforms based on natural PMLA}

In the early 2000s, Ljubimova et al. have developed a new type of nanoconjugates based on natural PMLA and called Polycefins ${ }^{\mathrm{TM}}$ [29-50]. As mentioned above for other nanovectors, the natural PMLA has been harvested from the culture broth of $P$. polycephalum microplasmodia [21]. The crude PMLA was purified and characterized with Mw between 50 and $100 \mathrm{kDa}$ with a polydispersity index of 1.3 before being subjected to a series of chemical modifications leading to the synthesis of an all-new set of polymers and the corresponding nanoplatforms $[41,42]$.

Taking advantage of the carboxylates' lateral groups, Ljubimova et al. have set up a method allowing a highly controlled chemical coupling of various molecules of interest to the polymeric PMLA backbone [29-50]. The carboxylate lateral groups were first activated under N-hydroxysuccinimidyl esters [41-43,45], then the different molecules of interest, called "modules" [43], were chemically coupled to the activated PMLA following a particular sequence mainly defined by the molecule sensitivity and the reactive groups $[43,45]$.

The first series of chemical coupling consisted in the addition of the more stable molecules through amide bonds:

- The PEG module $\left(\mathrm{m}-\mathrm{PEG}_{5000}-\mathrm{NH}_{2}\right)$ for protecting the nanoplatforms against unspecific degradation and scavenging [29-31,33-49].

- Endosome escaping modules which can be activated in response to acidic $\mathrm{pH}$ in mature endosomes/lysosomes. Different modules have been tested: the valine $[35,41]$, the leucine ethylester (LeuEt) [29-31,33,34,36-40,43-48] and the tri-leucine (TriLeu) $[29,31,33,34,40,45-48]$. The evaluation of the membrane lysis by natural PMLA substituted by various amino acid derivatives has demonstrated that: (i) natural PMLA derivatives having a pH-dependent membrane lysis property, such as natural PMLA substituted by the TriLeu, allowed safe and efficient cytoplasmic delivery [32-34,46], and that (ii) natural PMLA derivatives with $\mathrm{pH}$-independent membrane lysis properties, such as natural PMLA 
substituted by the LeuEt, were cytotoxic at high concentrations for several cell lines. Nevertheless, some of these $\mathrm{pH}$-independent natural PMLA derivatives can be used for transmembrane drug delivery under certain circumstances [32-34,46]. Moreover with the goal to design nanoplatforms with optimal cytoplasmic delivery efficiency and reduced systemic toxicity, the mechanisms of membrane permeation for two endosome escaping modules, LeuEt and TriLeu have been studied [33]. Natural PMLA bearing TriLeu had a pH-response membrane disruption by the "barrel-stave" mechanism (formation of aggregates in solution followed by insertion into the membrane forming trans-membranal pores leading to membrane permeation) and was less cytotoxic with a more efficient cytoplasmic delivery than the nanoplatforms bearing LeuEt, characterized by a "carpet" mechanism (binding to the membrane with high affinity leading to membranolysis in a cooperative manner) and a $\mathrm{pH}$ independent membrane disruption [33].

- A thiol-containing spacer module allowing the chemical coupling of other molecules such as targeting agent, drugs or fluorescent dyes [29-31,33-36,38,40-46]. The bioactive molecules were then chemically coupled to natural PMLA derivatives through thioether bonds for monoclonal antibodies [mAbs] and disulfide bonds for anti-sense oligonucleotides (AONs), the disulfide bonds being cleaved by cytoplasmic gluthatione to release free AONs [29-31,34-37,39-46]. A fluorescence dye, mainly the Alexa Fluor 680, was also introduced before masking the non-reacted thiol groups for in vitro and in vivo imaging [29-31,34-37,3946].

Two anti-cancer drugs, the Temozolomide hydrazide (TMZH) $[47,48]$ and the Dox [49], have also been chemically bound to natural PMLA nanoplatforms using labile bounds, hydrazide bound for TMZH and hydazone linker for Dox.

From the various natural PMLA based nanoplatforms, Ljubimova et al. performed in vitro and in vivo assays in order to evaluate the potential of their nanoplatforms as personalized nanomedecine in the field of anti-cancer drug delivery [29-50].

In collaboration with Ljubimova's team, Muñoz-Guerra et al. have prepared and characterized nanoplatforms based on partially methylated natural PMLA (25\% and 50\% of methylation) obtained by reaction of diazomethane on natural PMLA [50]. These authors have shown that degradation of methylated natural PMLA nanoplatforms was faster in human plasma than in phosphate buffered solution (PBS) and faster for low methylated derivatives [50]. Several cell based in vitro assays using nanoplatforms based on either $25 \%$ or $50 \%$ methylated natural PMLA have been realized in order to validate their use as biodegradable and biocompatible drug delivery systems. They evidenced that only the nanoplatforms 
constituted by $50 \%$ of methylated natural PMLA have a membrane disruption activity, property that can be useful to deliver drugs into cells [50]. Besides, in vitro cytotoxicity assays conducted on several cancer cell lines have shown that methylated natural PMLA exhibited an increasing toxicity with the degree of methylation related to the release of methanol occurring during the degradation of the corresponding methylated nanoconjugates [50]. In addition, cellular uptake studies realized with Rhodamine-labeled copolymers showed a homogenous fluorescence repartition within cells with a higher intensity observed for polymers having a higher methylation degree [50].

Besides nanoplatforms formulated with methylated natural PMLA, the other systems developed by Ljubimova et al. lead to encouraging in vitro and in vivo results. First of all, concerning in vitro evaluation of Polycefins ${ }^{\mathrm{TM}}$ carrying low molecular weight anti-cancer drugs (TMZH and Dox) have been coupled [47-49], the major conclusions are the following:

- The half-life of the conjugated TMZH has been significantly increased compared to that of free TMZH and the degradation of the nanoconjugates bearing the TMZH drug was faster at $37^{\circ} \mathrm{C}$ than at $4{ }^{\circ} \mathrm{C}$ and in human plasma versus PBS $[47,48]$.

- The release of Dox from the nanoconjugate Nat-PMLA/PEG ${ }_{5000}(5 \%) / \mathrm{GH}-\mathrm{Dox}(5 \%)$ was pH-dependent with a fast release at pH5 (about $75 \%$ of release after 10 hours of incubation) and almost no Dox release at pH7 [49].

- Membrane destabilization studies have evidenced that substitution of around $40 \%$ of pendant natural PMLA carboxylates of the platform by LeuEt ( $\mathrm{pH}$-independent) or TriLeu ( $\mathrm{pH}$-dependent) lead to good candidates for endosome disruption $[47,48]$.

- Cell viability studies, realized on human glioma cells U87MG (TMZH \& Dox), T98G (TMHZ) and U251 (Dox) and on invasive breast carcinoma cells, MDA-MB-231 and MDA-MB-468 (TMZH \& Dox), have evidenced that: (i). the Nat-

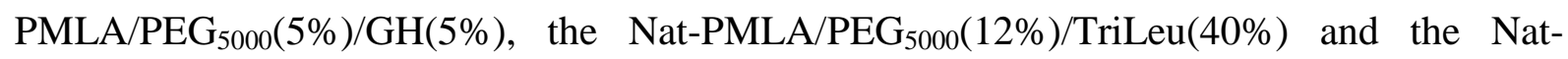
PMLA/TriLeu(40\%) were well tolerated by all cell lines within the studied concentration [4749]; (ii). the Nat-PMLA/PEG $5000(12 \%) / \operatorname{LeuEt}(40 \%)$ decreased significantly the cell viability and was not further considered [47,48]; (iii). the Nat-PMLA/PEG ${ }_{5000}(5 \%) / G H-D o x(5 \%)$ followed a dose dependent response similar to that of free Dox [49]; in this case, the authors suggested adding to the nanoplatform monoclonal antibodies as targeting agent to improve in vivo targeted delivery of Dox [49]; (iv). the leads compounds NatPMLA/TriLeu(40\%)/TMZH(17\%) and Nat-PMLA/PEG ${ }_{5000}(2 \%) / \operatorname{TriLeu}(40 \%) / \mathrm{TMZH}(17 \%)$ on which an anti-human transferrin monoclonal antibody (HuTfR mAb, 0.25\%) has been grafted showed a significant decrease in the studied tumor cell viability (human glioma and 
human breast cancer cell lines) $[47,48]$; in this case also, the authors proposed to move to in vivo assays with these two Polycefins ${ }^{\mathrm{TM}}$.

The major part of the research conducted by Ljubimova's group is devoted to the design of Polycefins ${ }^{\mathrm{TM}}$ grafted with $\mathrm{PEG}_{5000}$, anti-sense oligonucleotides [AONs] as anticancer drugs, one or two monoclonal antibodies [mAbs] as targeting agents, Lvaline/LeuEt/TriLeu as membrane disrupting units and, in some cases, a fluorescent dye [29,33-37,39,41-46]. They performed several in vitro studies using various human glioma cell lines and human breast cancer cell lines, as well as in vivo assays with mice or rats bearing either human breast cancer or human glioma cancer. They have shown that the Nat$\mathrm{PMLA}_{\mathrm{PEG}}{ }_{5000}(5 \%) / \mathrm{AON} 1(2.5 \%) / \mathrm{AON}_{2}(2.5 \%) / \mathrm{PEG}_{3400}-\mathrm{mAb}-\mathrm{OX} 26(0.23 \%) /$ valine(49\%) entered U87MG cells via a transferrin receptor-mediated endocytosis and that conjugated AONs efficiently inhibited target protein expression. After intra-venous injection of Polycefin $^{\mathrm{TM}}$ labeled with Alexa Fluor 680 dye in nude mice in which human brain cancer cells were implanted, the in vivo imaging experiment showed that Polycefin ${ }^{\mathrm{TM}}$ accumulated in the tumors because of the ability of this polymeric nanoconjugate to cross the Brain-TumorBarrier (BTB) [41]. After its intracranial injection in nude rats bearing human U87MG glioblastoma cells, a reduction of the expression of laminin- 8 ( $\alpha 4$ and $\beta 1$ ) chains and of the tumor vessel density along with an increase in animal survival have been observed without significant effect on other tissues and organ morphology [35].

A Polycefin ${ }^{\mathrm{TM}}$ bearing a mouse monoclonal anti-human transferrin receptor (TfR) antibody was shown to accumulate preferentially in brain and breast tumors after intra-venous injection into nude mice and in a lesser extent into kidney and liver leading the authors to conclude that Polycefins ${ }^{\mathrm{TM}}$ might be of great interest as anti-cancer treatment [44].

To improve direct tumor targeting, they prepared a new Polycefin ${ }^{\mathrm{TM}}$ derivative bearing PEG chain, AONs, LeuEt and two monoclonal antibodies with different specificities: the mouse monoclonal anti-human TfR antibody and the mouse monoclonal tumor-specific antinucleosome antibody 2C5 [36]. The authors demonstrated that this Polycefin ${ }^{\mathrm{TM}}$ was internalized in U87MG cells in vitro thank to the presence of the $2 \mathrm{C} 5$ antibody able to recognize the nucleosomes bound to an unknown surface receptor on the glioma cells [36]. After its intra-venous injection into nude mice intracranially implanted with human glioma cell line U87MG, the highest drug accumulation was observed with Polycefin ${ }^{\mathrm{TM}}$ bearing both mTfR and 2C5 mAbs: the anti-mouse TfR antibody allowed transporting drug through the BTB by binding specifically to the endothelium-expressed TfR and the anti-nucleosome $2 \mathrm{C} 5$ antibody allowed targeting human tumor cells by binding to a tumor cell surface antigen [36]. 
In their attempt to improve their nanoplatform, Ljibumova et al. have modified the targeting agents and the endosome escaping module. For that purpose, they chemically linked to the Polycefin $^{\mathrm{TM}}$ backbone two monoclonal antibodies, one targeting the BTB (mouse TfR) and one targeting tumor cells (human TfR), together with AONs targeting the laminin and the development of the angiogenesis within the tumor, and a $\mathrm{pH}$-activated TriLeu as endosome escape module [30,31]. Results have shown that:

- AONs were efficiently delivered by Nat-PMLA/TriLeu/AON/human TfR into the cytoplasm of U87MG and T986 glioma cells and inhibited the synthesis of Laminin-411 $\alpha 4$ and $\beta 1$ chains (Western blot analysis). Confocal analysis with double-labeled nanoplatform confirmed the entry of the nanoplatform and AONs in the U87MG and T986 glioma cells and its escape from the endosome pathway [30,31].

- The Nat-PMLA/TriLeu/AONs/mouse TfrR/human TfR showed the highest accumulation 24 hours after its intra-venous injection in human U87MG cells forming brain tumors implanted in mice. It should be noted that some of the drug was found in liver and kidney. These results suggested that this nanoplatform might be able to pass through the BTB and be efficiently internalized into the tumor cells [30,31].

- In these experiments, the tumor growth was significantly decreased after systemic injection of the nanoplatform in mice bearing intracranial human glioma U87MG cells,. Indeed, the tumor was $90 \%$ smaller in nanovector treated mice than in mice treated with PBS. Observation of brain sections of nanoplatform-treated mice evidenced mainly tumor remnants with significant necrosis and decreased tumoral angiogenesis [Ding, 2009, 2010]. The immunostained tumor sections showed a significant decrease in the staining intensity for both laminin chains with vessels having sizes almost similar to those in normal brain [30,31].

In view of these results, the Polycefin ${ }^{\mathrm{TM}}$ nanoplatforms seem to be very promising candidates to treat brain diseases.

Recently, Ljubimova's group evaluated the Polycefin ${ }^{\mathrm{TM}}$ nanoplatforms for breast cancer treatments $[29,33,37-39,46]$. In a first study, they have prepared a Polycefin ${ }^{\mathrm{TM}}$ nanoplatform conjugated with: (i) AON directed against HER2/neu mRNA to block new HER2/neu receptor synthesis, (ii) anti-HER2/neu antibody trastuzumab [Herceptin] to target breast cancer cells and inhibit receptor activity, (iii) transferrin receptor antibody to target the tumor vasculature and mediate nanoplatform delivery through the endothelial system, (iv) the LeuEt (40\%) as endosomal escape module to achieve cytoplasmic delivery of the AON and (v) a $\mathrm{PEG}_{5000}$ chain $(5 \%)$ to improve nanoplatform blood-stream stability [37,38]. They first realized in vitro experiments on cells expressing high (BT-474 and SKBR-3) and low (MDA- 
MB-231 and MDA-MB-435) HER2/neu levels. They showed that the Nat-PMLA/HER2/neu AON/LeuEt/Herceptin/human TfR/PEG 5000 nanoplatform was able to inhibit both the growth of all the breast cancer cell lines and the phosphorylation of serine/threonine kinase (Akt). Moreover, Ljubimova et al. showed that their Polycefin ${ }^{\mathrm{TM}}$ was able to triggered apoptosis in both high and low HER2/neu expressing cell lines in vitro [37,38]. Based on these encouraging results, they investigated the therapeutic effect of their developed Polycefin ${ }^{\mathrm{TM}}$ after intra-venous injection in nude mice bearing subcutaneous human breast tumor xenografts (BT-474 cell lines). The treatments were well tolerated by mice upon administration of the Polycefin ${ }^{\mathrm{TM}}$. The treatment induced tumor growth inhibition with a synergic effect of the presence of HER2/neu AON and Herceptin, and appearance of necrotic areas with little tumor tissue remaining [37,38]. Western-blot analysis of tumors after treatments showed that Polycefin ${ }^{\mathrm{TM}}$ induced strong and sustained inhibition of HER2/neu tumor expression and phosphorylation of Akt, as well as the induction of apoptosis [37,38]. These results constitute a proof of concept for the use of natural PMLA nanoplatforms for cancer therapy.

With the aim to improve the treatment of HER2/neu positive breast cancer, Ljubimova and coworkers have slightly modified the nanoplatform described above. Because Interleukin2 (IL-2) can be considered as a potential cancer treatment with, however, a low therapeutic efficacy due to its rapid blood clearance and severe side effects [51], they designed a natural PMLA nanoplatform bearing, among other modules, a modified human IL-2, which was obtained by its fusion to the C-terminus of the heavy chains of an anti-HER2/neu IgG3, antiHER2/neu IgG3-(IL-2) [29,34]. This Polycefin ${ }^{\mathrm{TM}}$, called PMLA-fusion nanobioconjugate, containing $5 \%$ of mPEG $_{5000}$ chains, $40 \%$ of LeuEt, $0.25 \%$ of anti-human-HER2/neu IgG3(IL-2) to target the tumor and function as immunomodulator while $2.5 \%$ of AONs trigger the inhibition of both human and mouse Laminin expression ( $\alpha 4$ and $\beta 1$ chains) [34]. After showing that IgG3-(IL-2) conjugated to natural PMLA retained the HER2/neu targeting properties of the anti-body and that the biological activity of the IL-2 within the complex antiHER2/neu IgG3-(IL-2) was maintained, Ljubimova et al. evaluated, by confocal microscopy, cellular uptake of the PMLA-fusion nanobioconjugate by BT-474 human breast cancer cells expressing high level of HER2/neu. Their results suggested that the presence of antiHER2/neu IgG3-(IL-2) on the nanoplatform allowed both the cell surface binding and the cellular uptake of the nanobioconjugate [29,34]. In vivo biodistribution studies were realized on athymic mice subcutaneously injected with BT-474 human breast cancer cells and after intra-venous injection of PMLA-fusion nanobioconjugate without AONs. The 
nanobioconjugate preferentially accumulated at the tumor site and in a lesser extent in the liver [29,34]. Anti-cancer activity and immunoactivation by the PMLA-fusion nanobioconjugate were also evaluated after intra-venous injection in a syngeneic model of immunocompetent BALB/c mice implanted with D2F2/E2 cancer cells [29,34]. Results evidenced that only treatment with the PMLA-fusion nanobioconjugate increased the survival of treated mice and the serum level of anti-HER2/neu IgG1 and IgG2a. Such results suggested an enhanced of the humoral and cellular immune responses $[29,34]$.

Furthermore, Ljubimova et al. adapted their Polycefin ${ }^{\mathrm{TM}}$ nanoplatform to the treatment of triple-negative breast cancer (TNBC) [39,46]. In a first study, they chemically bound to natural PMLA nanoplatform 5\% of m-PEG $5000,40 \%$ of LeuEt, $2 \%$ of epidermal growth factor receptor (EGFR) AON to inhibit the synthesis of EGFR, protein highly expressed in TNBC, $0.12 \%$ of anti-tumor nucleosome-specific monoclonal antibody mAb [2C5] to target breast cancer cells and $0.12 \%$ of anti-mouse transferrin receptor (TfR) antibody for delivery through the endothelium of blood vessels [39]. Western-blot analysis performed on EGFR expressing cells (MDA-MB-468) and cells expressing low EGFR levels (SKBR-3) demonstrated that Polycefin $^{\mathrm{TM}}$ derivative efficiently inhibited EGFR expression in both cell lines. To confirm the tumor targeting property of $\mathrm{mAb} 2 \mathrm{C} 5$, a variant of Polycefin ${ }^{\mathrm{TM}}$ containing $\mathrm{mAb} 2 \mathrm{C} 5$ and EGFR-AON was injected intra-venously into athymic mice bearing MDA-MB-468 human breast cancer cells. The biodistribution study showed that this nanobioconjugate accumulated mainly in tumor with a non negligible accumulation in kidney and liver. The introduction of the second antibody, the TfR, on the Polycefin ${ }^{\mathrm{TM}}$ nanoplatform allowed to a more important drug accumulation into implanted tumor an a reduced accumulation into kidney and liver [39].

Finally, the Nat-PMLA/PEG ${ }_{5000} /$ EGFR-AON/mAb 2C5/TfR/LeuEt was intra-venously injected into MAD-MB-468 tumor-bearing mice: this Polycefin ${ }^{\mathrm{TM}}$ induced the most pronounced anti-cancer effect with a strong tumor growth inhibition, a significant necrotic effect in treated tumor, a high inhibition of EGFR expression and of phospho-Akt levels in tumor [39]. In view of their results, the authors concluded that this new generation of nanobioconjugate might represent a powerful way to treat TNBC.

Before engaging Polycefins ${ }^{\mathrm{TM}}$ into clinical trials, Ljubimova and colleagues have performed a detailed evaluation of the toxicity and immunogenicity in vitro and in vivo of the Polycefin ${ }^{\mathrm{TM}}$ designed for TNBC treatment [46]. For this study, they have prepared a Polycefin $^{\mathrm{TM}}$ bearing AONs targeting EGFR, Laminin $\alpha 4$ and/or Laminin $\beta 1$ protein synthesis, LeuEt modules, $\mathrm{mPEG}_{5000}$, MsTfR mAb targeting mouse endothelial cells in tumor vessels 
and HuTfR mAb for binding to human tumor cells and nanodrug internalization. The investigators have shown that chronic exposure of nude mice to nanobioconjugates of natural PMLA at both low and high doses did not induce toxic changes in blood cell count or metabolic effects. PMLA nanoplatforms were well tolerated in vitro and in vivo in extreme dosage without toxicity and immune reactions. It is important to note that only low complement activation has been observed at very high dosage of the nanobioconjugate $(1 \mathrm{mg} / \mathrm{kg})$ [46]. In addition, Polycefin ${ }^{\mathrm{TM}}$ nanoplatforms inhibited the growth of EGFR-positive triple negative breast tumor cells in nude mice after intra-venous multiple injections. For both treatments, the Nat-PMLA/AON $\mathrm{EGFR}, \alpha 4, \beta 1_{1} / \mathrm{MsTfr} / \mathrm{HuTfR}$ nanoconjugate showed a significant tumor growth inhibition. These results lead the authors to conclude that this dual-action nanodrug significantly inhibited the TNBC growth and angiogenesis [46]. From the data, Polycefin $^{\mathrm{TM}}$ derivatives might be considered as versatile nanoplatforms for treatment of various cancers, such as breast and brain cancers, because of the possibilities to chemically couple several molecules of interest and the low toxicity and immunogenicity of the native natural PMLA backbone.

\section{Drug delivery systems based on synthetic poly(malic acid)}

Besides the use of natural PMLA derivatives for the design of drug delivery systems, synthetic poly( $\beta$-malic acid) has been the first polymer synthesized to be formulated as watersoluble drug carrier [52]. The chemical synthesis of PMLA has been conducted from two natural molecules, the malic acid [53] or the aspartic acid [54,55], and by different polymerization techniques, ring opening polymerization [54-56], polycondensation [57] or enzymatic polymerization using lipases [58]. The synthetic PMLA (Figure 1) is found under the $\beta$-form (ring opening and enzymatic polymerizations), the $\alpha$-form (ring opening polymerization) or a mixture of both $\alpha$ - and $\beta$-forms (polycondensation). These PMLAs have been successfully used to formulate of various drug delivery systems by several research teams.

First, applications of synthetic PMLA derivatives as macromolecular prodrugs are developed and summarized in Figure 3. 


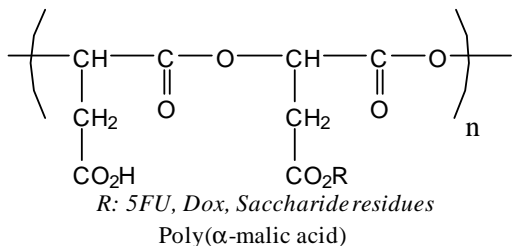

Water soluble drug carrier In vitro degradation

In vitro and in vivo assays [58-61, 103]

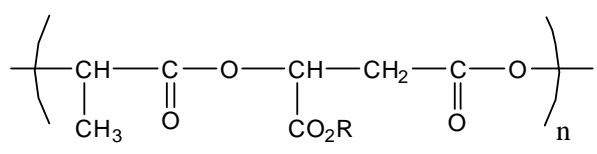

$R$ : $H$, hydroxyl arms, extented carboxyl arm or GRGDS Poly(lactide-co- $\beta$-malic acid)

Tissue engineering Physico-chemical characterization In vitro assays [70-76]<smiles>CC(C)OC(=O)CC(O)C(=O)C(C)(C)C</smiles>

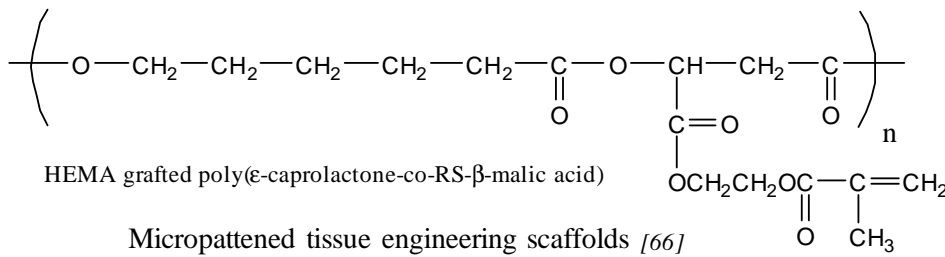
Micropattened tissue engineering scaffolds $[66$

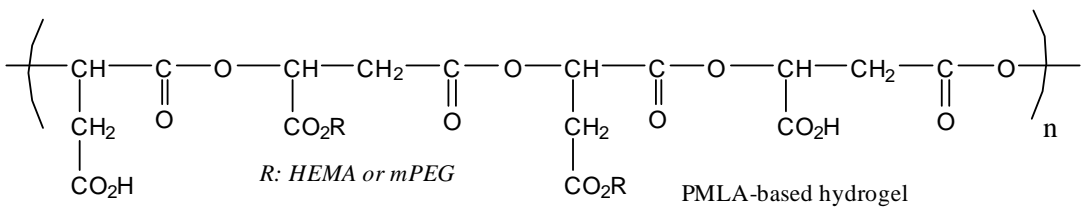

Degradable hydrogel

Physico-chemical characterizations

Dox encapsulation

In vitro assays $[67,68]$

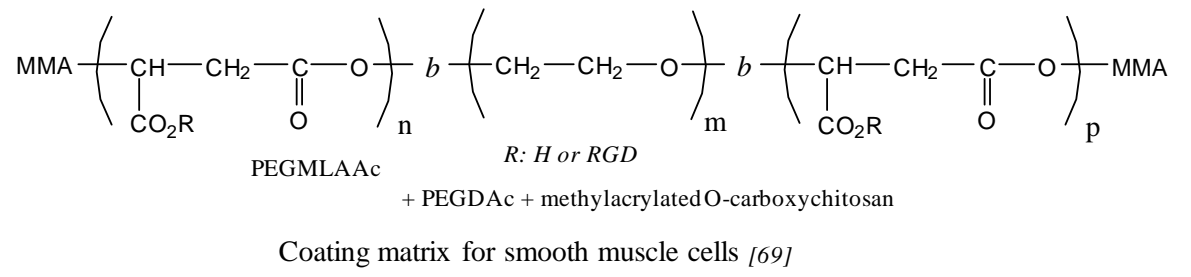

Figure 3. Structures and characteristics of water soluble synthetic PMLA derivatives.

In the early 1990s, Ouchi and coworkers have synthesized the poly( $\alpha$-malic acid) by ring-opening polymerization (ROP) of malide benzyl ester and have grafted the 5-fluorouracil (5FU) on this water soluble polyester anti-cancer drugs, [59-61] or the Dox [62-64].

The 5FU has been covalently linked to the carboxylic acid lateral group through ester, amide or carbanoyl bounds using classical coupling reactions [59-61]. Five saccharide 
residues have been also chemically coupled on poly( $\alpha$-malic acid)-5FU in order to evaluate the cell specific targeting of the resulting conjugate [60]. Ouchi et al. have first studied the degradation of their macromolecular conjugates in vitro in order to determine the release of 5FU from poly( $\alpha$-malic acid)-5FU conjugates [59-61]. They evidenced that the hydrolysis rates of the main-chain ester bonds of the poly( $\alpha$-malic acid)were much slower than those of lateral ester, amide and carbamoyl bonds leading to a slow release of 5FU [59-61]. The antitumor activity of poly( $\alpha$-malic acid)-5FU conjugates has been evaluated after intra-peritoneal injections into female CDF1 mice bearing P388 lymphocytic leukemia cells $[59,61]$. The poly( $\alpha$-malic acid)-5FU conjugates lead to an improved survival rate with no acute toxicity at a dose of $200-800 \mathrm{mg} / \mathrm{kg}[59,61]$. The conjugates bearing saccharide residues as targeting agent also seemed to have significant anti-tumor activities with no acute toxicity in the studied dose ranges after intra-peritoneal injection in the same animal model [60]. Ouchi et al. concluded that the 5FU side effects were significantly decreased by its attachment to poly $(\alpha-$ malic acid) backbone bearing or not saccharide residues as targeting agent [59-61].

Interestingly, the nature of the saccharide affected the in vitro growth inhibition in SKHep-1 and HLE human hepatoma cells and HeLa uterocervical carcinoma cells [60]. The poly( $\alpha$-malic acid)-5FU-galactosamine conjugate had the highest growth inhibitory effect on SK-Hep-1 and HLE cells while no effect has been observed on HeLa cells. Blocking the galactose receptors of human hepatoma cells with the trimer of galactosamino-saccharide induced a decrease in the growth inhibitory effect of poly( $\alpha$-malic acid)-5FU-galactosamine conjugates demonstrating that the galactosamide allowed targeting of 5FU to hepatoma cells via galactose-receptor [60].

The same group has also prepared a poly( $\alpha$-malic acid) derivate on which the Dox molecule was linked through ester or amide bounds [62]. As expected, the release rate of Dox conjugate to poly ( $\alpha$-malic acid) through ester bounds was faster than compared to that of Dox conjugated to poly( $\alpha$-malic acid) through amide bounds [62]. Cytotoxicity assays have been realized in vitro using P388 D1 lymphocytic leukemia cells. While the Dox linked to poly( $\alpha-$ malic acid) through ester bond induced a cytotoxicity similar to free Dox, the Dox bound to poly( $\alpha$-malic acid)through amide bound had a lower cytotoxicity [62]. Such results have led Ouchi's group to conjugate onto their poly( $\alpha$-malic acid)-amide-Dox various saccharide units as targeting agents and to study both the Dox release and the in vitro cytotoxicity of these conjugates on cancer cell lines [63,64]. As previously observed, free Dox was released faster from the poly $(\alpha$-malic acid) conjugates when Dox was linked through ester bonds and under acidic conditions compared to the poly( $\alpha$-malic acid)-amide-Dox [63]. The cytotoxicities of 
Dox linked to poly( $\alpha$-malic acid) were lower than with the free Dox [64]. The introduction of saccharide units seemed to have no influence on cytotoxicities of the corresponding Doxconjugates on AZ521, KNS and Hela cells. In contrast, the presence of galactosamine as saccharide units on the poly( $\alpha$-malic acid)-amide or ester-Dox had led to higher cytotoxicities on HLE and HepG2 hepatoma cells than those observed for non-glycosylated poly( $\alpha$-malic acid)-amide or ester-Dox and for free Dox $[63,64]$. The authors concluded that such higher activity resulted from galactose receptor-mediated uptake of the conjugate into hepatoma cells but further studies are still needed to confirm the interest of such poly( $\alpha$-malic acid)-Doxgalactosamine conjugates.

In a different context, copolyesters containing malic acid and propane 1,2-diol units have been also prepared with the goal to use them as enteric coating materials for tablets containing sodium diclofenac [65-67]. Bakr et al. have shown that the physico-chemical properties of the copolyesters remained unchanged in simulated gastric fluid ( $\mathrm{pH} 1.2)$ but these polymers gradually degraded in simulated intestinal fluid ( $\mathrm{pH} 7.4)$. These authors have evidenced that $80 \%$ of the sodium diclofenac were released within $45 \mathrm{~min}$ at $\mathrm{pH} 7.4$ and concluded that the release patterns of malic acid copolyesters coated tablets might correspond to the British Pharmacopea drug release profile of enteric coated tablets [65-67]. Despites such results and to the best of our knowledge, no additional data have been published for these applications.

In 2005, Chan-Park et al. have synthesized and characterized a 2-hydroxylethyl methacrylate (HEMA) grafted on poly( $\varepsilon$-caprolactone-co-RS- $\beta$-malic acid) with the goal to prepare functionalized and photopatternable biodegradable polyester for applications in micropatterned tissue engineering scaffolds [68]. These authors have concluded that their liquid copolymer possessed the required properties for UV microembossing, a liquid micromodeling technique, [68]. However, to date neither in vitro nor in vivo assays have been reported.

In the domain of the preparation of biocompatible materials based on PMLA derivatives, some research works have been realized on the synthesis and characterization of PMLA-based hydrogel [69-71]. He et al. prepared a poly( $\alpha, \beta$-malic acid) by polycondensation of malic acid, on which they grafted HEMA molecules using classical coupling reactions. The resulting poly $(\alpha, \beta$-malic acid)-graft-HEMA was then UV-crosslinked in presence of Irgacure 2959 as photoinitiator in water thus leading to the expected hydrogel [69]. These authors realized only physico-chemical characterization of the obtained hydrogel: water uptake, which varied in function of the HEMA content, and degradation behavior. They found that 
degradation was related to HEMA content and occurred simultaneously at the surface and in the bulk [69]. He and colleagues al. further modified poly( $\alpha, \beta$-malic acid)-based hydrogel prepared a supramolecular injectable hydrogel by mixing methylated-poly(ethylene glycol)graft-poly $(\alpha, \beta$-malic acid) [mPEG- $g$-poly $(\alpha, \beta$-malic acid)], obtained by coupling mPEG on $\operatorname{poly}(\alpha, \beta$-malic acid) [70]. The polyrotaxanes obtained by mixing mPEG-poly $(\alpha, \beta$-malic acid $)$ and $\alpha$-cyclodextrin ( $\alpha$-CD) in water were shown to act as physical cross-linked hydrogel with properties (gelation condition, hydrogel morphology, etc.) depending on their composition especially the content of copolymer and $\alpha-\mathrm{CD}$ and the molecular weight of mPEG. Dox-HCl has been encapsulated within the network with amounts varying between 0.015 and 0.034 wt $\%$ depending on the network composition. The Dox- $\mathrm{HCl}$ release in $\mathrm{PBS}$ at $37^{\circ} \mathrm{C}$ was quite fast within the first hours of incubation and was shown to be dependent on the hydrogel composition [70]. Finally, the anti-tumor effect of the released Dox-HCl was evaluated in vitro on U87MG glioma cancer cells. The variation of cell morphologies and the growth inhibition of cancer cells led the authors to conclude that their injectable hydrogel might be a new drug delivery system injectable in the vicinity of the tumor with minimal invasiveness $[70]$.

Finally, Chan-Park and coworkers have prepared and characterized biodegradable hydrogel based on PMLA derivatives as drug delivery systems [71]. A block copolymer PMLA- $b$-PEG- $b$-PMLA was synthesized by polymerization of benzyl malolactonate in presence of PEG and modified by addition of methacrylate groups on both chain ends (PEGMLAAc). These authors mixed methacrylated O-carboxychitosan (OCMCS), PEGMLAAc and PEG diacrylate (PEGDAc) in various proportions in water. These solutions were able to form hydrogels after photopolymerization of acrylate groups [71]. On the PMLA block of the hydrogel, the carboxylic acid lateral groups were used to chemically link the ArgGly-Asp (RGD) peptide. The RGD-grafted hydrogels were used as coating matrix for smooth muscle cell (SMCs) that have grown over time with no apparent toxicity. These hydrogels were shown to be degradable with a moderated release of malic acid at physiological $\mathrm{pH}$. Therefore, such PMLA-based hydrogels might be considered as promising coating substrate for long-term cell culture and proliferation [71].

In the design of biodegradable materials for tissue engineering, poly(lactide-co-malic acid) copolymers were synthesized by ring-anionic polymerization of lactide (L or DL emantiomer) and RS-benzyl malolactonate [72-78]. The authors studied the properties of such biodegradable polymers in terms of degradation rates, thermal properties and morphology of the block copolymers. All these parameters varied upon the copolymer composition and the 
synthesis temperature [72,73]. The various synthesized copolymers were then evaluated for cell colonization and biocompatibility as well as for tissue engineering [74-78]. He and coworkers have tested the cell adhesion on films prepared from poly(L-lactide-co- $\beta$-malic acid) using 3T3 mice fibroblasts. Their study evidenced that these fibroblasts could grew well on both the surface and inside the scaffolds [74].

With the aim of designing biocompatible matrices that would support cell culture, the authors have also evaluated the potential of the amorphous biodegradable poly(L-lactide-co- $\beta$ malic acid) grafted or not with bioactive RGD peptide to allow the culture of primary umbilical artery smooth muscle cells [75]. The cell viability was improved and their proliferation and spreading were shown to be better on films made by poly(L-lactide-co- $\beta$ malic acid) with or without RGD peptide than on films prepared from PLA [75]. Poly(Llactide-co- $\beta$-malic acid) polymers also support the culture of SMCs leading the authors to conclude that their functionalized copolymers might be of interest for vascular tissue engineering [76].

Few years later, another research team evaluated the uses of films based on poly(Llactide-co- $\beta$-malic acid) on which they grafted hydroxyl or extended carboxyl arms [78] or Gly-Arg-Gly-Asp-Ser (GRGDS) peptide [77] for vascular tissue engineering. In the search of an ideal biocompatible material for vessel engineering, Wang et al. synthesized a PMLAbased copolymer with extended carboxyl arms to enhance cell adhesion of endothelial cells and improve hemocompatibility [78]. They compared the properties of this new copolymer to the PMLA-based copolymers with hydroxyl arms and PLA in terms of degradation rates, water uptakes, surface morphologies, platelet adhesion, hemacompatibilities and Human umbilical vein endothelial cells (HUVECs) attachment and proliferation [78].

The results of their studies showed that the degradation rates of poly(lactide-co- $\beta$ malic acid) with pendant hydroxyl arms (PMLA-HE) and poly(lactide-co- $\beta$-malic acid) with extended carboxyl arms (PMLA-ECA) were similar with slow degradation rates during the first month accelerating thereafter. The intrinsic and extrinsic coagulation times representing the hemocompatibility were not influenced by the presence of both copolymers. The PMLAECA reduced, however, significantly the adhesion of blood platelets without activating them while allowing the best HUVECs attachment and proliferation [78].

Finally, Wang and colleagues evaluated the blood compatibility of poly(L-lactide-co$\beta$-malic acid) on which a GRGDS peptide has been grafted [77]. This copolymer, containing 9\% of malic acid units and 2.9 mol\% of carboxyl residues linked to GRGDS peptide, was shown to: (i) possess a quite high hydrophilicity; (ii) activate neither the intrinsic nor the 
extrinsic coagulation pathway; (iii) significantly decrease the adhesion and activation of blood platelets; (iv) promote the adhesion and proliferation of HUVECs [77]. Coagulation assays and platelet adhesion were also studied on the HUVECs plated on the copolymers: no difference was observed before and after cell seeding. From their results, the authors concluded that the cells cultured on their films showed a good anti-thrombogenicity and that these biodegradable films might be of interest for vascular tissue engineering [77].

All these results have highlighted that it is possible to modulate physico-chemical properties (degradation rate, hydrophilicity, biocompatibility, etc.) of PMLA derivatives by either grafting adapted lateral groups or by copolymerization with other monomers such as LA.

Besides the design of macromolecular water soluble prodrugs, hydrogels and films, numerous studies have been conducted on the elaboration of biodegradable nanoparticulate systems for site-specific delivery of drugs (Figure 4).

In this field, Stolnik et al. published the first results on the preparation and characterization of biodegradable colloidal particles prepared from amphiphilic PMLA derivatives [79-81]. Different poly( $\beta$-malic acid-co-benzyl malate) copolymers were synthesized by anionic ROP of benzyl malolactonate followed by partial catalytic hydrogenolysis. These authors performed only physico-chemical characterization of the corresponding particulate systems and showed that their size, surface charge and surface chemistry varied considerably with the copolymer composition: the presence of malic acid units resulted in the formation of larger nanoparticles with a significant decrease in zeta potential $[79,80]$. The degradation rates of such nanospheres were slow and most likely varied with copolymer composition: the presence of benzyl ester functions reduced the hydrolysis rate of ester bonds in the polymer main chains [81]. Even though such systems seemed to be of interest as drug delivery systems, no in vitro and in vivo assays have yet been published.

Over a decade ago, Osanai and colleagues have studied the effects of the complexation between liposomes and PMLA on aggregation and encapsulation behavior with the goal to prepare $\mathrm{pH}$-sensitive liposomes [82]. The authors prepared a poly(sodium- $\beta$-DL-malate-cooctyl- $\beta$-DL-malate) by copolymerization of benzyl malolactonate and octyl malolactonate followed by catalytic hydrogenolysis. This copolymer was then mixed with the soy lecithin L, $\alpha$-dipalmitoyl phosphatidylcholine (DPPC) to formulate liposomes with a polymer corona [82]. The obtained liposomes were shown to have a spherical structure with diameters in the range of 30 to $55 \mathrm{~nm}$, the octyl groups introduced on the PMLA working as anchors stabilizing therefore the complexation between lipid and PMLA [82]. Osanai et al. studied the 
influence of the $\mathrm{pH}$ on aggregation and fusion of liposomes as well as on the calcein release from the liposomes. Through their study, they showed that the aggregation and fusion were low at neutral $\mathrm{pH}$ and increased under acidic $\mathrm{pH}$ conditions. The same behavior was observed for calcein release, low at neutral $\mathrm{pH}$ and faster under acidic conditions [82]. These nanovectors have unfortunately not been further characterized despite these interesting features.

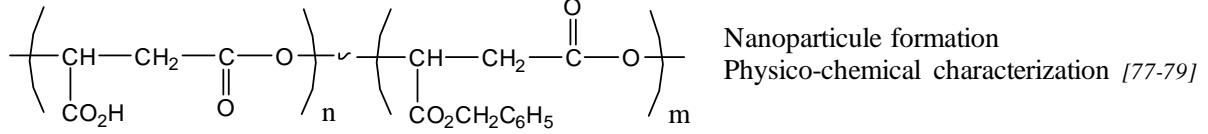

$$
\begin{aligned}
& \text { Poly( } \beta \text {-malic acid-co-benzyl malate) }
\end{aligned}
$$

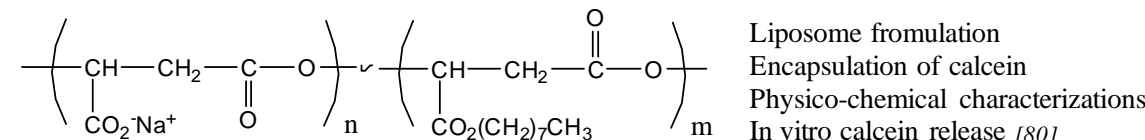

$$
\begin{aligned}
& \text { Poly(sodium } \beta \text {-DL-malate-co-octyl } \beta \text {-DL-malate) }+ \text { DPPC }
\end{aligned}
$$

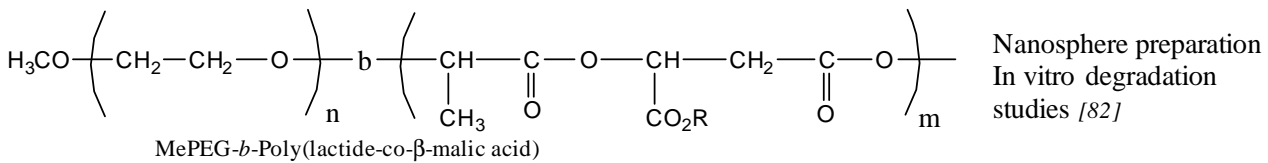

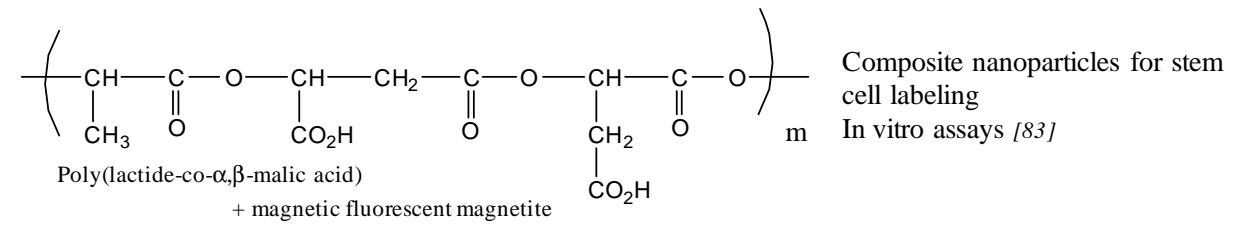

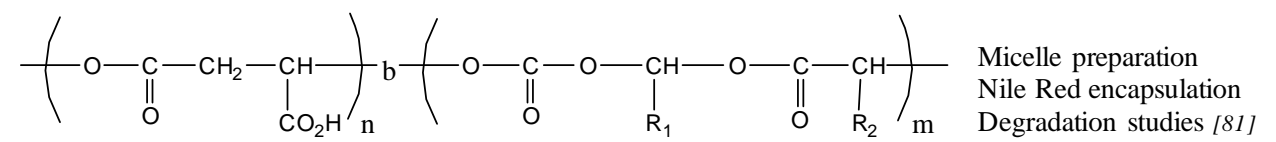$$
\mathrm{R}_{1}=\mathrm{R}_{2}=\mathrm{CH}_{3} \text { : PMLA- } b \text {-poly (lactide) }--\mathrm{R}_{1}=\mathrm{R}_{2}=-\left(\mathrm{CH}_{2}\right)_{5} \mathrm{CH}_{3} \text { : PMLA- } b \text {-PDiHeLA }
$$$$
\mathrm{R}_{1}=-\left(\mathrm{CH}_{2}\right)_{5} \mathrm{CH}_{3}, \mathrm{R}_{2}=\mathrm{CH}_{3}: \text { PMLA- } b \text {-PMoHeLA }
$$

$$
\mathrm{R}_{1}\left(\mathrm{CH}_{2}-\mathrm{CH}_{2}-\mathrm{O}\right)_{\mathrm{n}} \mathrm{b}\left(\underset{\mathrm{O}}{\mathrm{C}}-\mathrm{CH}_{2}-\mathrm{CH}_{2}-\underset{\mathrm{CO}_{2} \mathrm{R}_{2}}{\mathrm{CH}}-\mathrm{O}-\underset{\mathrm{O}}{\mathrm{C}}-\left(\mathrm{CH}_{2}\right)_{5}-\mathrm{O}\right)_{\mathrm{m}}
$$

$$
\mathrm{R}_{1}=\mathrm{CH}_{3}, \mathrm{R}_{2}=\mathrm{C}_{12} \mathrm{H}_{25} \text { : PEG- } b-\operatorname{Poly}(\beta-
$$

$$
\mathrm{R}_{1}=\text { Folic acid, } \mathrm{R}_{2}=\text { Dox: PEG- } b \text {-Poly }(\beta-
$$
dodecyl malate-co- $\varepsilon$-caprolactone) malic acid (Dox)-co- $\varepsilon$-caprolactone)

$$
\text { Nanocapsule preparation } \quad \text { Targeted micelles }
$$

$$
\text { SiRNA loading Dox loading }
$$

In vitro and in vivo assays [85]

In vitro assays [86]

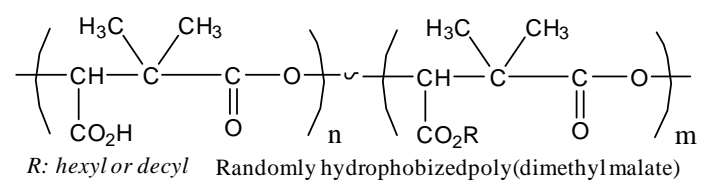

Hollow nanoparticles [91]

Nanoparticle formation

Amphotemicin or clofazimine loading In vitro degradation studies [92]

$$
\text { R: hexylor decyl Randomlyhydrophobizedpoly(dimethylmalate) }
$$

Chitosan modified by linoleic acid and PMLA

Nanoparticle formation

Paclitaxel or DNA loading

In vitro and in vivo assays $[87,88]$

\author{
Chitosan modified by poly(lactide-co- \\ $\alpha, \beta$-malic acid) \\ Polyelectrolyte complex \\ Dox encapsulation \\ In vitro assays [89]
}

PEG- $b$-poly $(\mathrm{L}-\beta-$ malic acid $)+$ PEG- $b$-poly(D- $\beta$-malic acid)

Sterocomplex micelles Physico-chemical characterization [90]

Figure 4. Structures and characteristics of synthetic PMLA derivatives under nano-object forms. 
Several studies also report studies realized with poly(lactide-co- $\beta$-malic acid) derivatives for the design of degradable nanoparticles [83-85]. Wang et al. have synthesized an amphiphilic di-block copolymer, the MePEG- $b$-poly(lactide-co- $\beta$-malic acid) by hydrogenolysis of the MePEG- $b$ - poly(lactide-co- $\beta$-benzyl malate) obtained by ring-opening copolymerization of DL-lactide and RS-benzyl malolactonate using MePEG as the initiator and stannous octoate as the catalyst [84]. The corresponding nanospheres were prepared by the solvent evaporation method The images obtained by TEM showed that the nanospheres prepared from the protected block copolymers had a compact spherical morphology while those prepared from the deprotected block copolymers had an incompact spherical morphology. Moreover, the in vitro experiments evidenced that the degradation rates increased with the amounts of hydrophilic malic acid units [84]. Unfortunately, no in vitro or in vivo assays have been realized so far on such nanospheres.

Recently, Nottelet et al. have prepared and characterized micelles based on the fully degradable block copolymers, the PMLA- $b$-poly(dihexyllactide), the PMLA- $b$ poly(monohexyllactide) and the PMLA- $b$-PLA. The first step consisted in the ring opening polymerization of benzyl malolactonate generating the PMLABe block which was used in the $2^{\text {nd }}$ step for the ring opening polymerization of dihexyllactide (DiHeLA), monohexyllactide (MoHeLA) or LA. The last step, catalytic hydrogenolysis of the PMLABe blocks, led to the expected amphiphilic block copolymers [83].

The corresponding micelles were prepared by adding an acetone solution of block copolymers into water or PBS at physiological $\mathrm{pH}$ under sonication. The resulting micelles varied in size with diameter ranging from 21 to $60 \mathrm{~nm}$ and their critical micellar concentration [cmc] between 7 and $100 \mathrm{mg} / \mathrm{L}$ [83]. Stability and loading capacity of these micelles evaluated with Nile Red fluorescence probe evidenced that the PMLA- $b$-PDiHeLA polymeric micelles presented: (i) an acceptable stability at room temperature, (ii) a reasonable stability during the first two weeks at $\mathrm{pH} 7.4$ and $37^{\circ} \mathrm{C}$ followed by a quite fast degradation, and (iii) a faster degradation at $\mathrm{pH} 5$ and $37^{\circ} \mathrm{C}$. The authors concluded that the properties of PMLA- $b$ PDiHeLA polymeric micelles might be of interest for controlled drug release in vivo [83].

The last study we wish to present here was conducted by Wang and coworkers in 2010 on biodegradable magnetic fluorescent magnetite/poly(lactide-co- $\alpha, \beta$-malic acid) composite nanoparticles for stem cell labeling [85]. The block copolymers were synthesized by two successive polycondensations: the DL-lactic acid was first polycondensated to give PLA on which DL-malic acid was polycondensated compound leading to the expected block copolymers. FITC was then grafted on some of the carboxylic acid lateral groups of the 
poly $(\alpha, \beta$-malic acid) block. Magnetite nanoparticles were then modified with the prepared fluorescent block copolymer and the resulting FITC-poly(lactide-co- $\alpha, \beta$-malic acid)-MNPs nanoparticles were subjected to several tests. First the magnetic properties of these nanoparticles have been evaluated and the results showed that they were suitable as magnetic resonance imaging T2-contrast agent. Moreover, these particles were shown to be non toxic towards RAW macrophages, 3T3 fibroblasts and human mesenchymal stem cells (hMSCs). In addition, FITC-poly(lactide-co- $\alpha, \beta$-malic acid)-MNPs were shown to be rapidly internalized into hMSCs and they had adverse effect on the osteogenic and adipogenic differentiation potentials of hMSCs. Finally, such interesting results led the authors to conclude that the magnetite nanoparticles they developed might be excellent magnetic fluorescent tracking agents for stem cells [85]. It is important to note that the use of PMLA, obtained by enzymatic polymerization using lipases, for surface coating of magnetic nanoparticles with applications as medical resonance imaging was patented [86].

With the goal to administrate new specific siRNAs able to target estrogen receptor alpha (Er $\alpha)$ without affecting ER $\beta$, Bouclier et al. studied the possibilities to load these siRNAs into nanocapsules constituted by PEG- $b$-poly( $\varepsilon$-caprolactone-co-dodecyle malate) block copolymers [87]. In this report, the authors described the synthesis and the physicochemical characterization of siRNA loaded nanocapsules as well as results of several in vitro and in vivo assays. The PEG- $b$-poly(e-caprolactone-co-dodecyle malate) based nanocapsules, prepared by double emulsion technique in presence or in absence of siRNAs, had a diameter of 105 to $118 \mathrm{~nm}$ across with a slightly negative zeta potential and a siRNA charge yield of $72 \%$ [87]. The PEG- $b$-poly(e-caprolactone-co-dodecyle malate) based nanocapsules were not toxic towards MCF7 cells in vitro. The authors investigated the time course of siRNA release from the nanocapsules and showed that the presence of proteins increased siRNAs release rate, and that a burst effect was observed followed by a period of slower release, phenomenon explained by the nanocapsules morphology [87]. Before moving to in vivo assays, the authors showed that siRNA loaded into PEG- $b$-poly( $\varepsilon$-caprolactone-cododecyle malate) nanocapsules significantly decreased the expression of Ero into MCF7 cells in vitro proving the efficient uptake of siRNA into cells [87]. Finally, siRNA loaded PEG- $b$ poly( $\varepsilon$-caprolactone-co-dodecyle malate) nanocapsules was intravenously injected into nude mice bearing estrogen-dependent brain cancer cell xenografts. Under the experimental conditions, the authors observed a significant decrease in Er $\alpha$ expression in tumors and a slight decrease in tumor growth [87]. The authors concluded that the formulations need to be 
optimized to lead to more significant effects on tumor regression but these nanocapsules, however, present a real potential as nucleic acids and drug carriers.

To prepare site-specific macromolecular micelles, Yang and colleagues utilized similar block copolymers of PEG-b-poly(e-caprolactone-co-malic acid), on which they introduced folic acid (FA) at the free chain end of the PEG block as targeting agent and Dox on lateral carboxylic acid lateral functions of the malic acid units through the $\mathrm{pH}$ sensitive hydrazone linker [88]. The obtained micelles had a diameter of about $25 \mathrm{~nm}$ with $14 \%$ of encapsulated Dox. At pH7.4, almost no Dox was released while the Dox release was increased at lower $\mathrm{pH}$ values. The FA-conjugated micelles were shown to be effectively uptaken by $4 \mathrm{~T} 1$ cells in vitro leading to the induction of cytotoxicity through the release of Dox [88].

Other interesting studies concern the design of either nanoparticles prepared from chitosan modified by linoleic acid and poly( $\beta$-malic acid) $[89,90]$ or polyelectrolyte complex (PEC) nanoparticles obtained by mixing poly(lactide-co- $\alpha, \beta$-malic acid)) with chitosan [91]. Yin et al. double grafted on chitosan the hydrophobic linoleic acid and a hydrophilic poly $(\beta-$ malic acid) having at one chain end lactic acid obtained by ring opening polymerization of benzyl malolactonate in presence of lactic acid [89,90]. In a first study, Yin et al. prepared nanoparticles by a sonication method, from the synthesized chitosan derivative. The obtained nanoparticles had diameters in the range of 190-330 nm with negative zeta potential (around $10 \mathrm{mV}$ ) while the critical aggregation concentration (CAC) was found to be dependent on the hydrophilic/hydrophobic ratio controlled by the number of linoleic acid and PMLA molecules grafted on the chitosan [89]. Paclitaxel (PTX) has been encapsulated into nanoparticles during the preparation step by sonication with loading efficiencies of around $70 \mathrm{w} \%$. The PTX release profile from all the prepared nanoparticles in vitro (PBS pH7.4 containing $0.1 \%$ of tween 80) showed a very fast PTX release within the first hour (burst effect) followed by a slightly slower PTX release. Almost $80 \%$ of encapsulated PTX were released after 12 hours of incubation. The in vitro hemolytic effects of the nanoparticles, representative of blood compatibility in vivo, were quite low, indicating that the prepared formulations might be suitable for intravenous injections and hematological applications [89]. Minimal acute toxicity has been observed for one of the formulations. Indeed, when this formulation was injected intravenously in mice at a dose of $625 \mathrm{mg} / \mathrm{kg}$, no sign of toxicity and death of animals have been observed. Moreover, a higher dose $(1250 \mathrm{mg} / \mathrm{kg})$ induced only moderate and transient signs of toxicity, which disappeared after 24 hours [89]. Eight days after the intravenous injection of this formulation loaded with PTX, tumor volume and weight were significantly 
decreased, meaning that PTX encapsulated into the chitosan based formulations was more effective than PTX alone [89].

In addition, Yin and colleagues have also prepared and characterized chitosan based formulation showing a positive surface charge for the encapsulation of DNA with the goal to develop degradable gene delivery systems. As described above, they synthesized amphiphilic linoleic acid and PMLA double grafted chitosan with substitution degree lower than those of the previous study [89] allowing them to obtain, by sonication of a buffered solution at pH5.5 containing the copolymer, nanoparticles with diameters varying from 170 to $260 \mathrm{~nm}$ and zeta potential between +30 to $+50 \mathrm{mV}$ [90]. They prepared the nanocomplexes by mixing these nanoparticles with the plasmid pEGFP encoding the Green Fluorescent Protein (GFP). Stable and uniform nanoparticle/pEGFP nanocomplexes were obtained at pH5.5 with diameter lower than $300 \mathrm{~nm}$. These researchers demonstrated that hydrophobic linoleic acid and hydrophilic PMLA substitutions allowed the suppression of non-specific adsorption, the reduction of interactions within the nanoparticle/pEGFP nanocomplexes and enhanced DNA release. On the other hand, they demonstrated that cell adsorption and uptake of the nanocomplexes were promoted by higher content of linoleic acid and lower PMLA substitution degree [90]. In vitro transfection assays on HEK 293 cells demonstrated that the nanocomplexes with a weight ratio of 12 had a high gene expression level with $34 \%$ of GFP positive HEK cells detected. This nanocomplexe has been selected for intramuscular transfection assay. It exhibited in vivo transfection capability superior to that observed for chitosan/pEGFP and poly(ethylenimine)/pEGFP nanocomplexes indicating that PMLA substituted chitosan might be of interest in the drug and gene delivery field [90].

In 2014, Wang and coworkers developed a PEC based on interactions between chitosan and the poly(lactide-co- $\alpha, \beta$-malic acid) which was obtained by polycondensation of L-malic acid and DL-lactic acid [91]. The authors observed that: (i) stable spherical nanoparticles were formed when the $\mathrm{pH}$ of the solution was in the range of 3 to 6 , (ii) their diameters were influenced by the composition of chitosan and the copolymers and were in the range of 300 to $600 \mathrm{~nm}$, (iii) the prepared PEC micelles had a negative surface charge of about $-30 \mathrm{mV}$, and (iv) their CAC varied from 0.009 to $0.105 \mathrm{mg} / \mathrm{ml}$ [91]. As a drug model, Dox was loaded into these PEC micelles and slightly increased the micelle diameter [91]. The drug release at different $\mathrm{pH}$ evidenced an initial burst effect within the first hours followed by a slower release regardless of the $\mathrm{pH}$ value [91]. In vitro cytotoxicity assays realized with the PEC nanoparticles on L929 cells showed that such nanovectors were not cytotoxic [91]. 
Despite inconsistent results, the authors concluded that their PEC micelles might be of interest as $\mathrm{pH}$ sensitive drug delivery systems [91].

An interesting study was realized by Dove et al. who prepared nanoparticles from stereocomplexation between PEG- $b$-poly(L- $\beta$-benzyl malate) and PEG- $b$ - poly(D- $\beta$-benzyl malate) which were synthesized by ring opening polymerization of R- or S-benzyl MLAR using PEG as macroinitiator and 4-methoxypyridine as catalyst [92]. These authors realized only partial physicochemical characterizations of their micelles showing that micelles formed by the stereocomplexation of both block copolyesters were more stable than the ones prepared from either PEG- $b$-poly(L- $\beta$-benzyl malate) or PEG- $b$-poly(D- $\beta$-benzyl malate) and might find applications as degradable polymeric micelles for drug delivery [92].

In 2011, Shen and colleagues have prepared and characterized biocompatible and biodegradable nanocapsules obtained by surface polycondensation of malic acid on silica nanoparticles as sacrificial templates [93]. The obtained poly $(\alpha, \beta$-malic acid $)$ grafted silica nanoparticles was cross-linked and the silica nanoparticles templates were eliminated leading to hollow polymeric nanocapsules [93]. Despite the lack of in vitro and/or in vivo assays, this kind of nanocapsules as well as their preparation strategy might be useful for the development of biocompatible nanovectors based on poly(malic acid) derivatives.

Recently, investigators utilized randomly hydrophobized poly(dimethylmalic acid) to solubilize water-insoluble drugs as Amphotenicin B (AmB) and clofazimine [94]. These authors first showed that the hydrophobized poly(dimethylmalic acid) copolymers were soluble in water under specific conditions of $\mathrm{pH}$ and salt concentration [94]. Solubilization of $\mathrm{AmB}$ and clofazimine with such PMLA derivatives was also dependent on the $\mathrm{pH}$ and salt concentration of the aqueous phase. Moreover, the degradation of hydrophobized poly(dimethylmalic acid) was not total even after 28 days of incubation [94]. Despite encouraging results, improvements are required in order to increase drug loading.

This part highlighted also the versatility of synthetic PMLA derivatives which can be synthesized in order to form nanoparticles able to entrapped hydrophobic drugs with properties (degradation and drug release rates, biocompatibility, etc.) adjusted to the targeted application. Moreover, through this rapid overview of works realized with synthetic PMLA derivatives, it seems obvious that such degradable and biocompatible polymer family might be of interest for the design of site-specific drug delivery using particulate nanovectors.

In this context, we have also developed PMLA derivatives (Figure 5) for the design of macromolecular materials for biomedical application $[18,95]$ and efficient site specific drug 
delivery nanoparticles [18,96-99]. All the PMLA derivatives we used were prepared by ring opening polymerization of $\beta$-substituted $\beta$-lactones synthesized from aspartic acid $[18,55]$.

The first step of our project was to determine whether PMLA derivatives could be used as water-soluble prodrugs $[18,95]$. For that, we have synthesized and characterized several PMLA derivatives with the goal to use them as: (i) degradable $\mathrm{pH}$-sensitive associating networks, (ii) fibroblast growth factor-like terpolymer, (iii) additive for peritoneal dialysis bags, or (iv) tissue engineering materials $[18,95]$.

To replace the potentially toxic silicone in the formulation of solutions contained into peritoneal dialysis bags, we synthesized a PMLA with a molecular weight of $15000 \mathrm{~g} / \mathrm{mol}$ which shown a high colloid-osmotic pressure. We, therefore, prepared peritoneal dialysis bags containing this PMLA and glucose and tested them on rats. Our results evidenced that bags containing $2 \%$ of the synthesized PMLA and $15 \mathrm{~g} / \mathrm{L}$ of glucose had the same ultrafiltration properties than bags containing $25 \mathrm{~g} / \mathrm{L}$ of glucose [18]. In view of these results, it might be of interest to develop such water soluble polyesters for applications as additive in the preparation of peritoneal dialysis bags.

As described earlier, biocompatible and degradable $\mathrm{pH}$-sensitive hydrogels had attracted the attention of several research groups. In this context, we have evaluated the potential of a poly( $\beta$-malic acid-co- $\beta$-malic acid adamantly ester) to form associative networks with a $\beta$-cyclodextrin $(\beta-C D)$ copolymer obtained by polycondensation of $\beta$-CD with epichlorohydrin [18]. Results of physico-chemical characterizations of the mixtures poly( $\beta$ malic acid-co- $\beta$-malic acid adamantly ester) $/ \beta-\mathrm{CD}$ copolymers demonstrated that a copolymer network could be obtained under appropriate conditions and that this network showed a $\mathrm{pH}$ sensitivity [18]. Therefore, this $\mathrm{pH}$-sensitive network might be of interest for the design of $\mathrm{pH}$-sensitive degradable hydrogel.

We also developed PMLA derivatives showing wound healing properties. For that purpose, we have synthesized a PMLA derivative bearing $60 \%$ of carboxylate lateral groups (PMLA), $30 \%$ of sulfonate lateral groups and $10 \%$ of hydrophobic butyl malate units using the versatility of both the monomers and polymer's synthesis [18]. These three specific lateral groups have been selected because they were known to interact with natural heparin sulfates (HS)-related molecules. Results of in vitro assays showed that the synthesized terpolymer was able to protect and stabilize FGFs while results of in vivo experiments evidenced that the terpolymer was able to favor muscular regeneration similarly to the most active functionalized dextrans mimicking HS functions towards FGFs [18]. These encouraging results evidenced 
that we were able to prepare macromolecular PMLA derivates with properties adjusted to the envisaged biomedical application.

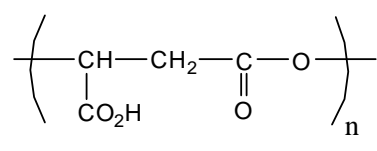

$\operatorname{Poly}(\beta$-malic acid $)$

Additive for peritoneal dialysis bag In vitro assays [18]

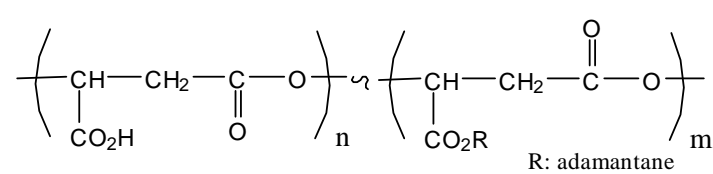

Poly ( $\beta$-malic acid-co- $\beta$-malic acid adamantyl)

$\mathrm{pH}$-sentive hydrogels

Physico-chemical characterization [18]

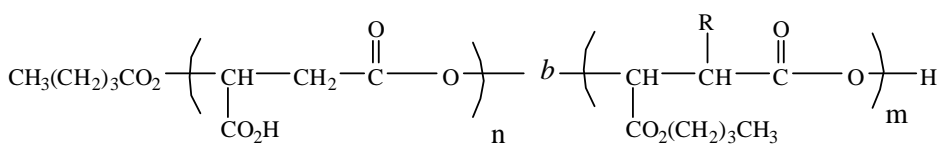

$\mathrm{R}=\mathrm{H}: \mathrm{PMLA}_{43}$-b-PMLABu, $\mathrm{n}=43$ \& $\mathrm{m}=7$

$\mathrm{R}=\mathrm{CH}_{3}: \mathrm{PMLA}_{43}-\mathrm{b}-\mathrm{PMeMLABu}_{10}, \mathrm{n}=43 \& \mathrm{~m}=10$ PMLA $_{83}-\mathrm{b}-\mathrm{PMeMLABu}_{14}, \mathrm{n}=83$ \& $\mathrm{m}=14$

Macromolecular micelles

Physico-chemical characterization

Pyrene encapsulation [18,19]<smiles>CCC(=O)C(CC(=O)OC(C)(C)C)C(C)(C)CC(C)(OC(=O)CC(C(=O)OCC(=O)OC(C)(C)CC(C(=O)[O-])C(C)(C)C)C(C)(C)C)C(=O)OC(C)(C)C</smiles>

Fibroblast growth factor like terpolymer $\quad \mathrm{CH}_{2} \mathrm{CH}_{2} \mathrm{SO}_{3}{ }^{-} \mathrm{Na}^{+}$ In vitro and in vivo assays [18]

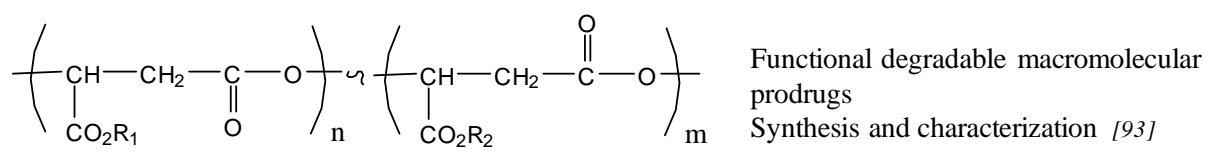

$\mathrm{R}_{1}$ : 3-methyl-2-butenyl,3-methyl-3-butenyl,3,7-dimethyl-2,6octadienyl,w-methyloxycarbonyloligolactyl, cholesteryl or phenylmethyl

$\mathrm{R}_{1}=\mathrm{R}_{2}$ : Polyesters - or $-\mathrm{R}_{2}=\mathrm{CH}_{2} \mathrm{C}_{6} \mathrm{H}_{5}$ : Copolyesters

$\left(\underset{\mathrm{CO}_{2} \mathrm{R}_{1}}{\mathrm{CH}}-\mathrm{OH}_{2}-\underset{\mathrm{O}}{\mathrm{C}}-\mathrm{O}\right)_{n} n\left(\underset{\mathrm{CO}_{2} \mathrm{R}_{2}}{\mathrm{CH}}-\mathrm{CH}_{2}-\stackrel{\mathrm{O}}{\mathrm{C}}-\mathrm{O}\right)_{\mathrm{m}}$

$\mathrm{R}_{1}=\mathrm{R}_{2}=$ benzyl, isopropyl, neohexylor hexyl: poly(alkylmalate) $\mathrm{R}_{1}=\mathrm{H}, \mathrm{R}_{2}=$ hexyl: poly (malic acid-co-hexyl malate)<smiles>[R]C(C)(C)OC(=O)CC(CC(=O)OCCC(C)(C)OCCC(C)(C)C)C(C)(C)OCCC</smiles>
$\mathrm{R}=\mathrm{H}: \mathrm{PEG}_{42}-b-\mathrm{PMLABe}_{68}$ $\mathrm{CO}_{2} \mathrm{CH}_{2} \mathrm{C}_{6} \mathrm{H}_{5}$ $\mathrm{R}=\mathrm{FA}: \mathrm{PEG}_{42}-b-\mathrm{PMLABe}_{68}-\mathrm{FA}$

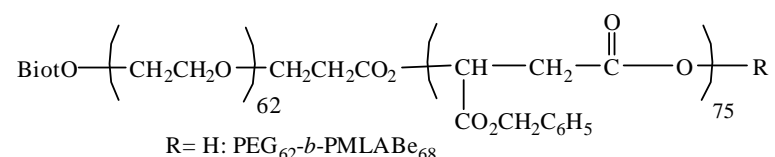

$\mathrm{R}=\mathrm{H}: \mathrm{PEG}_{62}-b-\mathrm{PMLABe}_{68}$ $\mathrm{R}=\mathrm{FA}: \mathrm{PEG}_{62}-b$-PMLABe ${ }_{68}-\mathrm{FA}$
Nanoparticle preparation

Physico-chemical characterization

Halofantrin encapsulation

In vitro assays [18,97]
Nanoparticle preparation Physico-chemical characterization Dox encapsulation In vitro and in vivo assays $[95,96]$

Figure 5. Structures and characteristics of synthetic PMLA derivatives.

In collaboration with Professor Chiellini's team, we have prepared and characterized a series of polyesters and copolyesters from newly synthesized malolactone monomers with the goal to use them as bioerodible and biodegradable functional macromolecular prodrugs [95]. This preliminary study was essentially dedicated to the set up of optimal conditions for 
monomers and polymer's preparation. The characteristics of the prepared PMLA derivatives appeared promising for future biomedical applications.

Despites the interesting results we obtained with water soluble PMLA derivatives, we have next chosen to concentrate our research works on the design of nanoparticulate systems based on various hydrophobic or amphiphilic PMLA derivatives for site-specific drug delivery [18,96-99].

The first nanoparticulate systems we developed were based on the hydrophobic PMLA derivatives, poly(benzyl malate), poly(isopropyl malate), poly(neohexyl malate), poly(hexyl malate) and poly(malic acid-co-hexyl malate) [18,99].

Nanoparticles were prepared by the nanoprecipitation method consisting in the addition of an acetone solution of the selected polymer into an aqueous solution under stirring. After the evaporation of the organic solvent, the nanoparticles solutions were analyzed (dynamic light scattering; DLS) and evaluated in various in vitro assays. The diameters of the obtained nanoparticles were shown to be dependent on the nature of the repeating units and varied from 85 to $160 \mathrm{~nm}$.

It is worth to note that the zeta potentials were found to be around $-30 \mathrm{mV}$ whatever the polymer used to prepare the nanoparticles meaning that the terminal carboxylic acid functions were located at the surface of the nanoparticles [18,99]. We then investigated the degradation behavior of the prepared nanoparticles in various medium at $37^{\circ} \mathrm{C}$ by size exclusion chromatography (molecular weights of the polymers), proton nuclear magnetic resonance (NMR) (structure of the degradation products) and DLS (stability of the nanoparticles). As expected, results have shown that the degradation rates of the nanoparticles constituted by hydrophobic PMLA derivatives were slower than with nanoparticles of more hydrophilic PMLA derivatives. Moreover, we have shown that the degradation process seemed to be a phenomenon happening randomly in the polymer main chain $[18,99]$. Moreover, we have also demonstrated that the cytotoxicity measured using J774 A1 murine macrophage cells was rather mild and dependent upon the rate of degradation of the polymers forming the nanoparticles and on the formation of low molecular weight products [99]. Finally, we have investigated drug encapsulation capacity of two kinds of nanoparticles, the poly(isopropyl malate) and the poly(neohexyl malate) based nanoparticles, with halofantrin, a low water soluble drug used in the treatment of malaria [18]. The drug loadings were in the range of $5 \mathrm{wt} \%$, the diameters of the resulting charged nanoparticles were correlated to the amount of halofantrin added to the nanoprecipitation medium and an inversion of the zeta potentials with an increase in the initial amount of halofantrin was observed. We assumed that 
a part of the drug might be adsorbed at the surface of the nanoparticles. As expected, the release of halofantrin was faster in intestinal medium than in PBS and a burst effect was observed with $50 \%$ of halofantrin released after $30 \mathrm{~min}$ of incubation [18]. All these results were very encouraging because they proved that PMLA derivatives might be used as versatile polymeric materials for the design of efficient drug delivery systems.

Therefore, to improve our nanoparticulate systems, we concentrated our efforts on the design of fully degradable macromolecular micelles in collaboration with the Professor Kataoka's team $[18,96]$. To fulfill this objective, we synthesized and characterized three amphiphilic block copolymers: poly(malic acid $)_{43}-b$-poly(butyl malate $)_{7}$, poly(malic acid $)_{43}-b-$ poly(butyl malate $)_{10}$ and poly(malic acid $)_{83}-b$-poly(butyl malate $)_{14}$ [96].

Because of the presence of carboxylic acid lateral groups on the hydrophilic PMLA block, we had to set up a protocol to obtain stable micelles under conditions ( $\mathrm{pH}$, salinity, etc.) compatible with in vivo applications. After testing several micellization techniques, we were able to obtain stable macromolecular micelles by direct dissolution of the amphiphilic block copolymers in $10 \mathrm{mM}$ phosphate buffered solution (PBS) at pH7.4 containing $0.15 \mathrm{M}$ $\mathrm{NaCl}$. The obtained micelles were characterized by DLS to determine their average diameter and their cmc, giving an idea of the micelle stability, was measured by fluorescence using pyrene as fluorescence probe [96].The prepared micelles had properties depending on the nature and length of each block constituting the amphiphilic block copolymers: the more stable micelles, with a diameter of $35 \mathrm{~nm}$ and a cmc of $8 \mathrm{mg} / \mathrm{L}$, were obtained with the block copolymer having (i) longer hydrophilic and hydrophobic blocks, (ii) a hydrophobic block with the higher degree of hydrophobicity, and (iii) a high hydrophilic/hydrophobic ratio [96].

Moreover, we have demonstrated that the obtained degradable micelles showed properties which were dependent on the $\mathrm{pH}$ of the solution. Therefore, such fully degradable macromolecular micelles might be of interest as $\mathrm{pH}$-sensitive drug carriers.

With the aim to design more efficient nanoparticulate systems for site-specific drug delivery, we have recently developed targeted stealth nanoparticles based on amphiphilic PMLA derivatives constituted by (i) a PEG hydrophilic block conferring stability and stealth properties to the resulting nanoparticles, and (ii) a PMLABe hydrophobic block forming the inner core of the nanoparticles in which hydrophobic drugs might be encapsulated $[97,98]$. We designed such site-specific nanoparticulate drug delivery systems with the goal to develop an efficient drug carrier to treat the Hepatocellular Carcinoma (HCC). Indeed, the HCC represents the main primary malignant tumor of the liver representing 80-90\% of liver tumor and, to date, only very few nanovectors based on polymeric nanoparticles carrying peptides 
with high tropism for the liver have been developed [100]. Therefore, we synthesized and characterized three PMLA derivatives: (i) a hydrophobic $\mathrm{PMABe}_{68}$, (ii) an amphiphilic $\mathrm{PEG}_{42}-b$-PMLABe 68 , and (iii) an amphiphilic block copolymer possessing a targeting moiety, the biotin, at the free end chain of the PEG block, Biot-PEG $62-b-\mathrm{PMLABe}_{75}[97,98]$. We selected the biotin as specific molecule for mainly two reasons The biotin is known to be a targeting agent of certain cancer cells [101-103] and it is able to strongly interact with streptavidin [104], property we have used to introduce specific short peptides on the outershell of the prepared nanoparticles in order to rapidly screen their specificity towards transformed hepatocytes in vitro with the final objective to further selected the most effective peptides for direct covalent grafting at the free end chain of the PEG block [98]. We have also prepared fluorescent PMLA derivatives by grafting a fluorescein amine molecule at the free end chain of the PMLABe block in order to visualize the corresponding nanoparticles into cells by flow cytometry of microscopy. Following the synthesis of both monomer and polymer, we were able to obtain well-defined PMLA derivatives.

Starting either from non fluorescent PMLA derivatives or from a mixture of non fluorescent and fluorescent block copolymers (50/50 wt\%), empty nanoparticles, drug (Dox) loaded-nanoparticles or fluorescent probes (1,1'-dioctadecyl-3,3,3',3'tetramethylindodicarbocyanine perchlorate, $\mathrm{DiD}$ oil, or 1,1'-dioctadecyl-3,3,3',3'tetramethylindotricarbocyanine iodide, DiR) loaded-nanoparticles were prepared by the nanoprecipitation technique leading to the obtention of well-defined nanoobjects in a reproducible manner [97,98].

In vitro cytotoxicity of empty $\mathrm{PMLABe}_{68}, \mathrm{PEG}_{42}-b$ - $\mathrm{PMLABe}_{68}$ and $\mathrm{Biot}_{-\mathrm{PEG}_{62}-b-}$ $\mathrm{PMLABe}_{75}$ based nanoparticles has been evaluated on several cancer cell lines (PC3, NCI, Caco, HCT116, MDA, HuH7 and mmt 060562) and human immortalized foreskin fibroblasts. These assays revealed that the nanoparticles prepared from the synthesized PMLA derivatives might be considered as non toxic in vitro for all the tested cell lines. Indeed, we observed a moderated decreased of the cell viability only for high polymer concentrations above $10 \mu \mathrm{M}$ [97].

Dox release kinetics from $\mathrm{PEG}_{42}-b-\mathrm{PMLABe}_{68}$ and Biot-PEG $62-b-\mathrm{PMLABe}_{75}$ based nanoparticles loaded with Dox were followed in water and in culture medium at $37^{\circ} \mathrm{C}$. As we could expected, we have observed a burst effect within the first hours of incubation with about $40 \%$ to $50 \%$ of Dox released after 10 hours followed by a slow release over the tested period (70 hours of incubation) [98]. The treatment of $\mathrm{HuH7}$ cells in vitro with Dox loaded into $\mathrm{PMLABe}_{68}, \mathrm{PEG}_{42}-b$-PMLABe 68 and $\mathrm{Biot}_{62} \mathrm{PEG}_{62}-b-\mathrm{PMLABe}_{75}$ based nanoparticles 
induced, as for the free Dox, a dose-dependent cytotoxicity with $\mathrm{IC}_{50} \mathrm{~s}$ similar to the one of free Dox. Such results were encouraging in the sense that the efficacy of Dox was not affected by the encapsulation process [97].

To study the biotin effect on cellular uptake in vitro with mmt 060562cells known to overexpress the biotin receptor, we have prepared $\mathrm{PEG}_{42}-b-\mathrm{PMLABe}_{68}$ and Biot-PEG $62-b-$ $\mathrm{PMLABe}_{75}$ based nanoparticles loaded with the fluorescence probe, DiD oil: the red fluorescence was only seen in cells that had uptaken DiD oil loaded into Biot-PEG $62-b$ $\mathrm{PMLABe}_{75}$ based nanoparticles [97].

These results evidenced that the tumor cell targeting with the biotin molecule was effective, but we have now to confirm this targeting by performing free biotin competition tests. Nevertheless, such results are encouraging and we hypothesized that in vivo treatment of biotin overexpressing tumor animal models might give interesting results.

As mentioned above, besides the use of biotin as a well-known cancer cell's targeting agent, we aimed at developing a versatile procedure to screen more specific targeting agents towards transformed hepatocytes in HCC. Our final goal is to select peptides exhibiting a very high tropism for the hepatocytes as targeting agents and to graft them at the free chain end of the PEG block in order to expose the grafted peptides at the surface of the PMLA derivativesbased nanoparticles. First, we wished to screen several peptides without engaging more organic synthesis in order to select the more active targeting agents. For that purpose, we used the non-covalent binding affinity between biotin ad streptavidin.

In this study, we used fluorescent nanoparticles constituted by a mixture of either $\mathrm{PEG}_{42}-b-\mathrm{PMLABe}_{68}+\mathrm{PEG}_{42}-b-\mathrm{PMLABe}_{68}-\mathrm{FA}(50 \mathrm{wt} \%)$ or Biot-PEG $62-b-\mathrm{PMLABe}_{75}+$ Biot-PEG $_{62}-b$-PMLABe ${ }_{75}-\mathrm{FA}(50 \mathrm{wt} \%)$. The presence of the FA molecule had no influence on the nanoparticle characteristics. Biotinylated cyclic RGD peptide (Arg-Gly-Asp-DTyrLys-Biot) was first associated to streptavidin followed by the addition of this complex to biotinylated fluorescent nanoparticles with defined conditions: $4 \mu \mathrm{M}$ of block copolymers, 4 $\mu \mathrm{M}$ of streptavidin and $8 \mu \mathrm{M}$ of biotinylated RGD peptide [98]. The dilution in PBS or in culture medium had no significant influence on biotinylated fluorescent nanoparticles. We observed a moderate increase in the diameter and polydispersity index of these nanoparticles after the addition of the complex Biot-cRGD/streptavidin in PBS and in culture medium.

In PBS and culture medium, we also observed a moderate formation of aggregates without destabilization of the nanoparticles. We assumed that such limited modifications might be considered acceptable for in vitro assays [98]. We therefore performed several in vitro assays with the RGD modified nanoparticles in order to evaluate their potential for 
further in vivo applications [98]. In vitro cell captation by human hepatoma HepaRG cell line of RGD-Biot-Streptavidin-Biot-fluorescent nanoparticles was followed using Facs and fluorescent microscopy (Figure 6).

The obtained data demonstrated that the addition of the RGD peptide to the biotinylated fluorescent nanoparticles led to a considerable enhancement of cellular uptake of the nanoparticles. The results of this analysis highlighted a rapid uptake within the 6 first hours which continued slower until 24 hours for RGD modified fluorescent nanoparticles while no uptake was observed for biotinylated fluorescent nanoparticles.

The specificity of the uptake of RGD modified fluorescent nanoparticles by HepaRG cells was evaluated by flow cytometry analysis in presence or in absence of an excess of free RGD: results demonstrated that the presence of the RGD peptide on the surface of nanoparticles was effectively responsible of the increased uptake by HepaRG cells of RGD modified fluorescent nanoparticles.
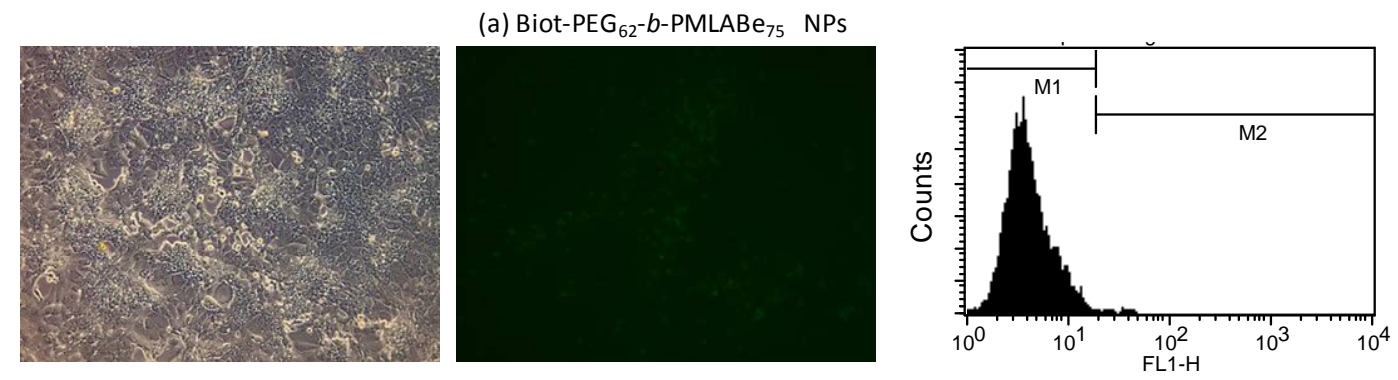

(b) Biot-PEG $62-b-\mathrm{PMLABe}_{75}+$ Biot-PEG $62-b-\mathrm{PMLABe}_{75}-\mathrm{FA}$ NPs
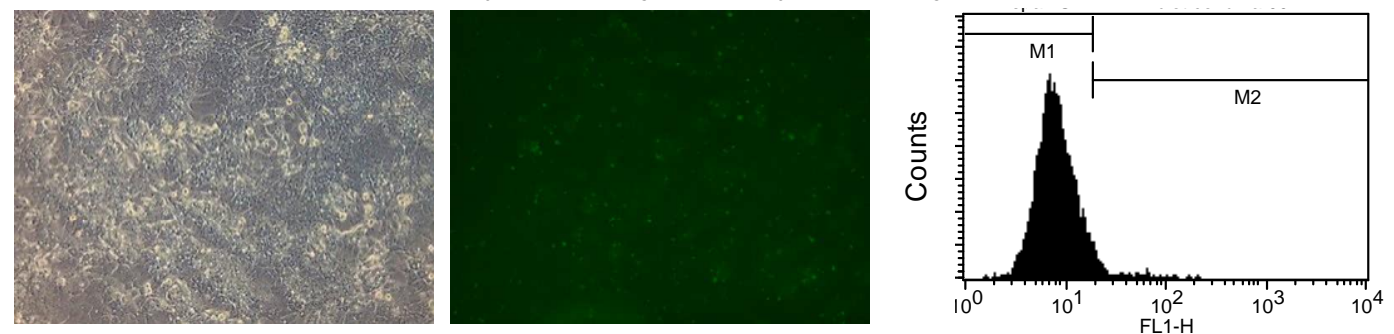

(c) RGD-biot/Streptavidin/Biot-PEG $62-b-\mathrm{PMLABe}_{75}+$ Biot-PEG $62-b-\mathrm{PMLABe}_{75}-\mathrm{FA}$ NPs
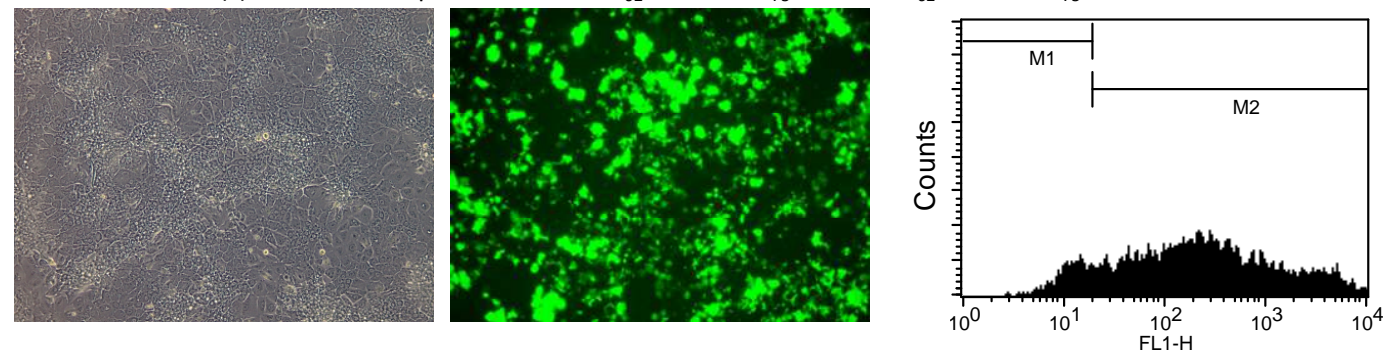

Figure 6. Fluorescence microscopy and flow cytometry analysis of HepaRG cells incubated with (a). Biot-PEG $62-b$-PMLABe 75 nanoparticles (NPs), (b). Biot-PEG $62-b-\mathrm{PMLABe}_{75}+$ Biot$\mathrm{PEG}_{62}-b$-PMLABe 75 -FA NPs, and (c). RGD-biot/Streptavidin/Biot-PEG $62-b-\mathrm{PMLABe}_{75}+$ Biot-PEG $62-b-$ PMLABe $_{75}-\mathrm{FA} \mathrm{NPs.}$ 
The uptake of biotinylated fluorescent nanoparticles and RGD modified fluorescent nanoparticles by three different cell lines (HepaRG, HT29 and HeLa cancer cells) was then studied by flow cytometry (Figure 7).

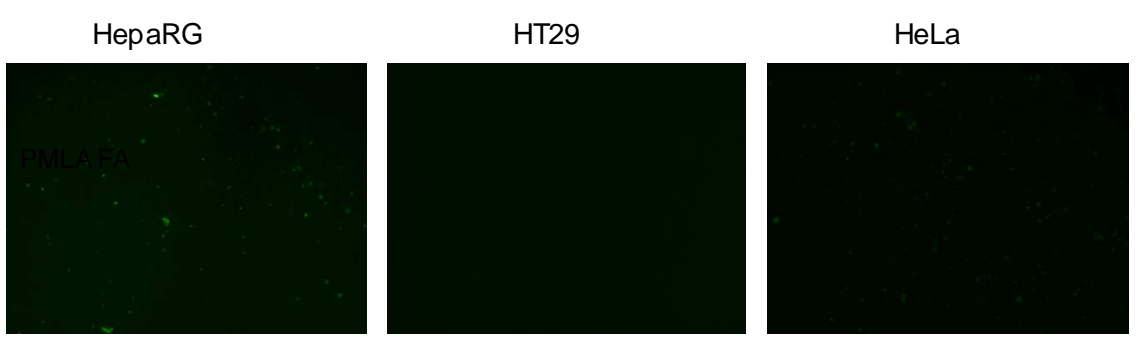

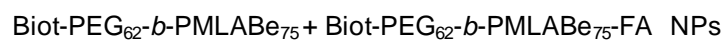

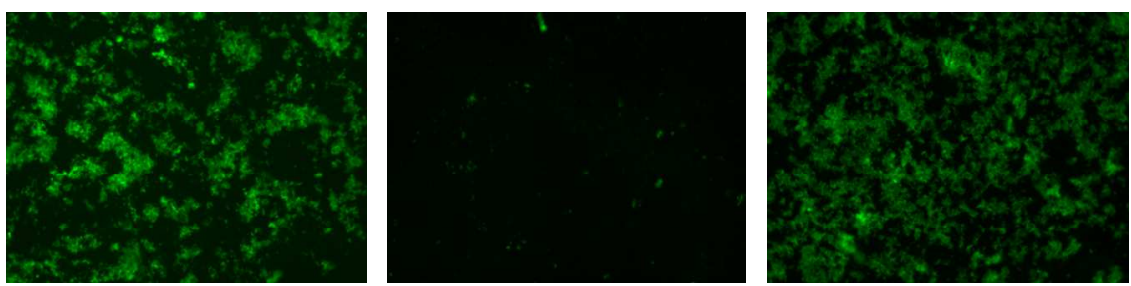

RGD-biot/Streptavidin/Biot-PEG ${ }_{62}-b-\mathrm{PMLABe}_{75}+$ Biot-PEG $_{62}-b-\mathrm{PMLABe}_{75}-\mathrm{FA} \quad \mathrm{NPs}$
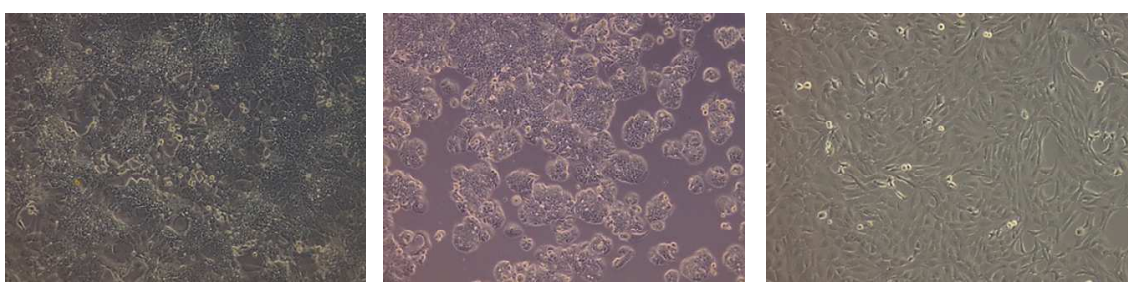

Phase contrast
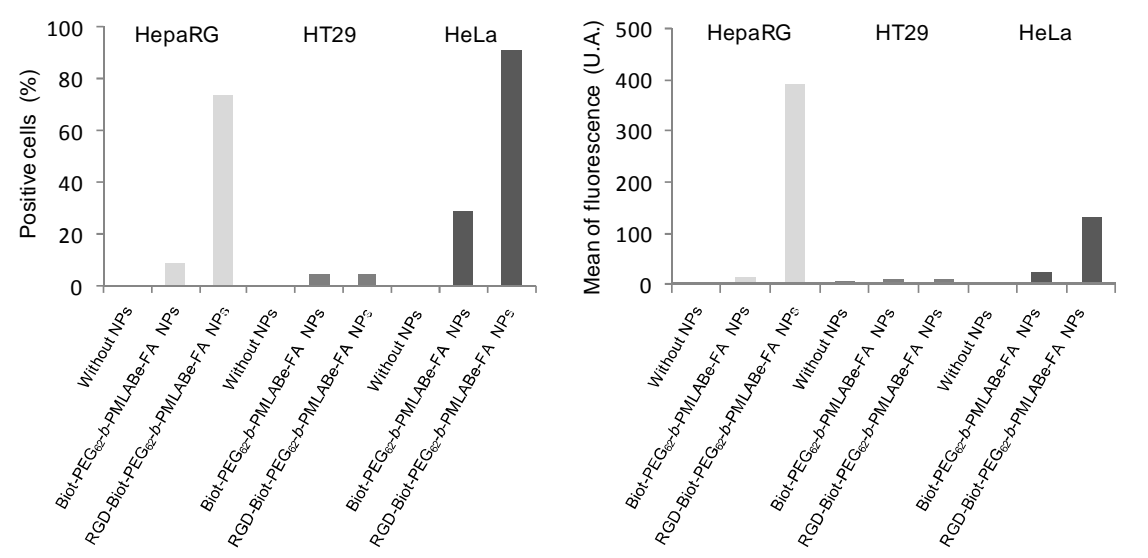

Figure 7. Fluorescence microscopy (upper panel) and flow cytometry analysis (charts on the lower panel) of HepaRG, HT29 and HeLa cells incubated with biotinylated fluorescent nanoparticles and RGD modified fluorescent nanoparticles for 24 hours.

The three cell lines showed low levels of fluorescence when they were incubated with biotinylated fluorescent nanoparticles. For HT29 cells, both the number of positive cells and the degree of uptake were very low. On the contrary, the number of positive HeLa cells was 
slightly higher than the one of positive HepaRG cells. However, the degree of uptake in HeLa cells was much lower than in HepaRG cells. Such results indicated that the RGD peptide had a real tropism for liver cells.

In our study, we demonstrated that the molecular scaffold Pept-Biot-Streptavidin-BiotNPs might be used to screen for other short peptides targeting hepatocytes and HCC. We have already selected short peptides ( $<20$ amino acids), which might present an interest for our studies. Our goal will be to select two or three of the more efficient peptides to graft them at the free chain end of PEG block to avoid the use of immunogenic streptavidin for further in vivo biodistribution assays.

In the meantime, we have already realized a preliminary in vivo study in nude BALB/c mice by intravenous injection of Biot- $\mathrm{PEG}_{62}-b-\mathrm{PMLABe}_{75}$ nanoparticles modified or not with RGD peptide and loaded with the DiR fluorescent probe. The preliminary results indicated that these nanoparticles were well tolerated with no signs of toxicity. Moreover, we were able to detect fluorescence in the living animal thus demonstrating that our experimental conditions were compatible with this kind of study. In addition, the first analyses seemed to highlight a more important abdominal accumulation of the RGD modified nanoparticles loaded with DiR in comparison to the biotinylated nanoparticles encapsulated DiR. We have now to confirm the exact localization of the RGD modified nanoparticles loaded with DiR. Moreover, we will move to the injection of directly modified nanoparticles by the selected peptides without the use of immunogenic streptavidine molecule to check their in vivo biocompatibility, biodistribution and efficiency against HCC.

\section{Conclusion}

Through this overview, we highlighted that both natural and synthetic PMLA derivatives might be considered as promising biocompatible and degradable polymeric materials for applications in the field of drug delivery systems. While a lot of works have been realized mainly by Ljubimova's groups on natural PMLA, only limited researches have been conducted on synthetic PMLA derivatives despites the interesting results already obtained. Until now, PMLA derivatives (either natural or synthetic ones) are still at the step of preclinical trials even if some in vivo assays have been conducted. At the moment, to the best of our knowedge, no phase III or clinical evaluations have been published despites encouraging results obtained on such materials. Therefore, we will continue our efforts to 
design efficient biocompatible nanoparticulate drug carriers based on synthetic PMLA derivatives for HCC treatments.

\section{Acknowledgements}

SCM wish to thank Professor Philippe Guérin who introduced her to synthetic PMLA domain and Professor Kazunori Kataoka who formed her to the drug delivery systems during her post-doctoral training in his team. This work was supported by Inserm, CNRS, the University of Rennes 1 (Défis émergents-2012) and les comités départementaux de la Ligue contre le Cancer du Grand Ouest (comités 29, 35 et 53).

\section{Declaration of interest}

This work was supported by Inserm, CNRS, the University of Rennes 1 (Défis émergents2012) and les comités départementaux de la Ligue contre le Cancer du Grand Ouest (comités $29,35$ et 53$)$.

\section{References:}

1. Ehrlich P. 1906. Collected Study on Immunology. John Wiley \& Sons: New York.

2. Torchilin VP. 2006. Multifunctional nanocarriers. Adv Drug Deliv Rev, 58, 15321555 .

3. Hoffman AS. 2008. The origins and evolution of "controlled" drug delivery systems. $J$ Control Release, 132, 153-163.

4. Liu S, Maheshwari R, Kiick KL. 2009. Polymer-based therapeutics. Macromolecules, $42,3-13$.

5. Malam Y, Loizidou M, Seifalian AM. 2009. Liposomes and nanoparticles: nano-sized vehicles for drug delivery in cancer. Trends Pharmacol Sci, 30, 592-599.

6. Misra R, Acharya S, Sahoo SK. 2010. Cancer nanotechnology: application of nanotechnology in cancer therapy. Drug Discov Today, 15, 842-850.

7. Park JH, Lee S, Kim JH, Park K, Kim K, Kwon IC. 2008. Polymeric nanomedecine for cancer therapy. Prog Polym Sci, 33, 113-137.

8. Chiellini F, Piras AM, Errico C, Chiellini E. 2008. Micro/Nanostructured Polymeric Systems for Biomedical and Pharmaceutical Applications. Nanomedicine, 3(3), 367393. 
9. Ho RJY, Chien JY. 2009. Clinical trials and translational medicine commentary. $J$ Pharm Sci, 98 (6), 1928-1934.

10. Kumari A, Yadav SK, Yadav SC. 2010. Biodegradable polymeric nanoparticles based drug delivery systems. Colloids and Surfaces B: Biointerfaces, 75, 1-18.

11. Ringsdorf H. 1975. Structure and properties of pharmacologically active polymers. $J$ Polymer Sci, 51, 135-153.

12. Pang X, Du HL, Zhang HQ, Zhai YJ, Zhai GX. 2013. Polymer-drug conjugates: present state of play and future perspectives. Drug Discovery Today, 18 (23/24), 13161322.

13. Yokoyama M, Miyauchi M, Yamada N, Okano T, Sakurai Y, Kataoka K, Inoue S. 1990. Polymer micelles as novel drug carrier - adriamycin-conjugated poly(ethylene glycol)poly(aspartic acid) block copolymer. J Control Release, 11, 269-278.

14. Kabanov AV, Chekhonin VP, Alakhov V, Batrakova EV, Lebedev AS, MelikNubarov NS, Arzhakov SA, Levashov AV, Morozov GV, Severin ES. 1989. The neuroleptic activity of haloperidol increases after its solubilization in surfactant micelles. FEBS Lett, 258, 343-345.

15. Piras AM, Chiellini F, Fiumi C, Bartoli C, Chiellini E, Fiorentino B, Farina C. 2008. A New Biocompatible Nanoparticle Delivery System for the Release of Fibrinolytic Drugs. Int J Pharm, 357(1-2), 260-271.

16. Dessy A, Piras AM, Dinucci D, Chiellini F. 2011. 2-Methoxy Aniline Grafted Poly(maleic anhydride- alt- butyl vinyl ether) Hemiester: A New Biocompatible Polymeric Free Radical Scavenger. Macromolecules. 44, 848-856.

17. Vert M, Lenz RW. 1979. Preparation and properties of poly- $\beta$-malic acid: a functional polyester of potential biomedical importance. Polym Preprints, 20 (1), 608-611.

18. Cammas S, Béar MM, Moine L, Escalup R, Ponchel G, Kataoka K, Guérin Ph. 1999. Polymers of malic acid and 3-alkylmalic acid as synthetical PHAs in the design of biocompatible hydrolyzable devices. Int J Biol Macromol, 25, 273-282.

19. Cammas-Marion S, Guerin Ph. 2000. Design of malolactonic acid esters with a large spectrum of specified pendant groups in the engineering of biofunctional and hydrolyzable polyesters. Macromolecular Symposia, 153, 167-186.

20. Jaffredo CG, Guillaume SM. 2014. Benzyl b-malolactonates polyesters: a long story with recent advances. Polym Chem, 5, 4168-4194. 
21. Fisher H, Erdmann S, Holler. E. 1989. An unusual polyanion from Physarum polycephalum that inhibits homologous DNA polymerase alpha in vitro. Biochemistry, 28 (12), 5219-5226.

22. Cammas S, Guérin Ph, Girault JP, Holler E, Gache Y, Vert M. 1993. Natural poly(Lmalic acid): NMR shows a poly(3-hydroxy acid)-type structure. Macromolecules, 26, 4681-4684.

23. García-Alvarez M, Martínez de Ilarduya A, Portilla JA, Alla A, Muñoz-Guerra S. 2008. Ionic complexes of biotechnological polyacids with cationic surfactant. Macomol Symp, 273, 85-94.

24. Lanz-Landázuri A, García-Alvarez M, Portilla-Arias JA, Martínez de Ilarduya A, Patil R, Holler E, Ljubimova J, Muñoz-Guerra S. 2011. Poly(methyl malate) nanoparticles : formation, degradation, and encapsulation of anti-cancer drug. Macromol Biosci, 11, 1370-1377.

25. Lanz-Landázuri A, García-Alvarez M, Portilla-Arias JA, Martínez de Ilarduya A, Holler E, Ljubimova J, Muñoz-Guerra S. 2012. Modification of microbial polymalic acid with hydrophobic amino acids for drug-releasing nanoparticles. Macromol Chem, 213, 1623-1631.

26. Portilla-Arias JA, García-Alvarez M, Martínez de Ilarduya A, Muñoz-Guerra S. 2007. Ionic complexes of biosynthetic poly(malic acid) and poly(glutamic acid) as prospective drug-delivery systems. Macromol Biosci, 7, 897-906.

27. Portilla-Arias JA, García-Alvarez M, Galbis JA, Muñoz-Guerra S. 2008. Biodegradable nanoparticles of partially methylated fungal poly( $\beta$-malic acid) as a novel protein delivery carrier. Macromol Biosci, 8, 551-559.

28. Portilla-Arias JA, García-Alvarez M, Martínez de Ilarduya A, Holler E, Galbis JA, Muñoz-Guerra S. 2008. Synthesis, degradability, and drug releasing properties of methyl esters of fungal poly( $\beta$-L-malic acid). Macromol Biosci, 8, 540-550.

29. Black KL, Ljubimova JY, Ljubimov AV, Holler E. 2012. Polymalic acid based nanoconjugate for imaging. WO 2012/139030 A1, PCT/US2012/03273.

30. Ding H, Ljubimova JY, Holler E, Black KL. 2009. Poly(beta-malic acid) with pendant leu-leu-leu tripeptide for effective cytoplasmic drug delivery. PCT Int Appl. WO 2009126913 A1.

31. Ding H, Inoue S, Ljubimov AV, Patil R, Portilla-Arias J, Hu J, Konda B, Wawrowsky KA, Fujita M, Karabalin N, Sasaki T, Black KL, Holler E, Ljubimova JY. 2010. 
Inhibition of brain tumor growth by intravenous poly( $\beta$-L-malic acid) nanobioconjugate with $\mathrm{pH}$-dependent drug release. PNAS, 107(42) 18143-18148.

32. Ding H, Portilla-Arias J, Patil R, Black KL, Ljubimova JY, Holler E. 2011. The optimization of polymalic acid peptide copolymers for endosomolytic drug delivery. Biomaterials, 32, 5269-5278.

33. Ding H, Portilla-Arias J, Patil R, Black KL, Ljubimova JY, Holler E. 2013. Distinc mechanisms of membrane permeation induced by two polymalic acid copolymers. Biomaterials, 34, 217-225.

34. Ding H, Helguera G, Rodríguez JA, Markman J, Luria-Pérez R, Gangalum P, PortillaArias J, Inoue S, Daniels-Wells TR, Black KL, Holler E, Penichet ML, Ljubimova JY. 2013. Polymalic acid nanobioconjugate for simultaneous immunostimulation and inhibition of tumor growth in HER2/neu-positive breast cancer. J Control Release, 171(3), 322-329.

35. Fujita M, Khazenzon NM, Ljubimov AV, Lee BS, Virtanen I, Holler E, Black KL, Ljubimova JY. 2006. Inhibition of laminin-8 in vivo using a novel poly(malic acid)based carrier reduces glioma angiogenesis. Angiogenesis, 9, 183-191.

36. Fujita M, Lee BS, Khazenzon NM, Penichet ML, Wawrowsky KA, Patil R, Ding H, Holler E, Black KL, Ljubimova JY. 2007. Brain tumor tandem targeting using a combination of monoclonal antibodies attached to biopoly( $\beta$-L-malic acid). J Control Release, 122(3), 356-363.

37. Inoue S, Ding H, Portilla-Arias J, Hu J, Konda B, Fujita M, Espinoza A, Suhane S, Riley M, Gates M, Patil R, Penichet ML, Ljubimov AV, Black KL, Holler E, Ljubimova JY. 2011. Polymalic Acid-Based Nanobiopolymer Provides Efficient Systemic Breast Cancer Treatment by Inhibiting both HER2/neu Receptor Synthesis and Activity. Cancer Res, 71(4), 1454-1464.

38. Inoue S, Ding H, Holler E, Black KL, Ljubimova JY. 2012. Polymalic acid-based nanobiopolymer compositions and methods for treating cancer. PCT Int Appl. WO 2012091718 A1.

39. Inoue S, Patil R, Portilla-Arias J, Ding H, Konda B, Espinoza A, Mongayt D, Markman JL, Elramsisy A, Phillips HW, Black KL, Holler E, Ljubimova JY. 2012. Nanobiopolymer for direct targeting and inhibition of EGFR expression in triple negative breast cancer. PLoS One, 7(2), 1-9, e31070.

40. Kateb B, Chiu K, Black KL, Yamamoto V, Khalsa B, Ljubimova JY, Ding H, Patil R, Portilla-Arias JA, Modo M, Moore DF, Farahani K, Okun MS, Prakash N, Neman J, 
Ahdoot D, Grundfest W, Nikzad S, Heiss JD. 2011. Nanoplatforms for constructing new approaches to cancer treatment, imaging, and drug delivery: What should be the policy? NeuroImage, 54, 5106-5124.

41. Lee BS, Fujita M, Khazenzon NM, Wawrowsky KA, Wachsmann-Hogiu S, Farkas DL, Black KL, Ljubimova JY, Holler E. 2006. Polycefin, a New Prototype of a Multifunctional Nanoconjugate Based on $\operatorname{Poly}(\beta$-L-malic acid) for Drug Delivery. Bioconjug Chem, 17(2), 317-326.

42. Ljubimova JY, Black KL, Holler E. 2005. Polymalic acid-based multifunctional drug delivery system. PCT Int. Appl. WO 2005055980 A2.

43. Ljubimova JY, Fujita M, Ljubimov AV, Torchilin VP, Black KL, Holler E. 2008. Poly(malic acid) nanoconjugates containing various antibodies and oligonucleotides for multitargeting drug delivery. Nanomedicine, 3(2), 247-265.

44. Ljubimova JY, Fujita M, Khazenzon NM, Lee BS, Wachsmann-Hogiu S, Farkas DL, Black KL, Holler E. 2008. Nanoconjugate based on polymalic acid for tumor targeting. Chem Biol Interac, 171, 195-203.

45. Ljubimova JY, Holler E. 2012. Biocompatible nanopolymers: the next generation of breast cancer treatment? Nanomedicine, 2012, 7(10), 1467-1470.

46. Ljubimova JY, Portilla-Arias J, Patil R, Ding $H$, Inoue S, Markman JL, Rekechenetskiy A, Konda B, gangalum PR, Chesnokova A, ljubimov AV, Black KL, Holler E. 2013. Toxicity and efficacy evaluation of multiple targeted polymalic acid conjugates for triple-negative breast cancer treatment. J Drug Target, 21(10), 956-967.

47. Patil R, Portilla-Arias J, Ding H, Inoue S, Konda B, Hu J, Wawrowsky KA, Shin PK, Black KL, Holler E, Ljubimova JY. 2010. Temozolomide Delivery to Tumor Cells by a Multifunctional Nano Vehicle Based on Poly( $\beta$-L-malic acid). Pharm Res, 27, 2317 2329.

48. Patil R, Holler E, Black KL, Ljubimova JY. 2011. Drug delivery of Temozolomide for systemic based treatment of cancer. PCT Int Appl. WO 2011/072240 A1.

49. Patil R, Portilla-Arias J, Ding H, Konda B, Rekechenetskiy A, Inoue S, Black KL, Holler E, Ljubimova JY. 2012. Cellular Delivery of Doxorubicin via pH-Controlled Hydrazone Linkage Using Multifunctional Nano Vehicle Based on Poly( $\beta$-L-Malic Acid). Int J Mol Sci, 13, 11681-11693.

50. Portilla-Arias JA, Patil R, Hu J, Ding H, Black KL, García-Alvarez M, Muñoz-Guerra S, Ljubimova JY, Holler E. 2010. Nanoconjugate platforms development based in 
poly( $\beta$-L-malic acid) methyl esters for tumor drug delivery. $J$ Nanomaterials, Article ID 825363, 8 pages doi:10.1155/2010/825363.

51. Negrier S, Maral J, Drevan M, Vinke J, Escudier B, Philip T. 2000. Long-term followup of patients with metastatic renal cell carcinoma treated with intravenous recombinant interleukin-2 in Europe. Cancer J Sci Am, 6(Suppl.1), S93-S98.

52. Vert M. 1986. Polyvalent polymeric drug carriers. CRC Crit Rev Ther Drug Carrier Syst, 2, 291-327.

53. Arnold SC, Lenz RW. 1986. Synthesis of stereoregular poly(alkyl malolactonates). Makromol Chem Macromol Symp, 6, 285-303.

54. Guérin Ph, Vert M, Braud C, Lenz RW. 1985. Optically active poly( $\beta$-malic acid). Polym Bull, 14, 187-192.

55. Cammas S, Renard I, Langlois V, Guérin Ph. 1996. Poly( $\beta$-malic acid) : obtaining high molecular weights by improvement of the synthesis route. Polymer, 37(18), 42154220.

56. Ouchi T, Fujino A.1989. Synthesis of poly( $\alpha$-malic acid) and its hydrolysis behavior in vitro. Makromol Chem Rapid Commun, 190, 1523-1530.

57. Otani N, Kimura Y, Kitao T. 1961. Preparation of poly(malic acid) and its ester derivatives by direct polycondensation of malic acid and $\beta$-ethyl malate. Konbushi Ronbunshu, 44, 701-709.

58. Matsumura S, Beppu H, Nakamura K, Osanai S, Toshima K. 1996. Preparation of $\operatorname{poly}(\beta$-malic acid $)$ by enzymatic polymerization of benzyl $\beta$-malolactonate. Chem Lett, 25(9), 795-796.

59. Ouchi T, Kobayashi H, Banda T. 1990. Design of poly( $\alpha$-malic acid)-5FU conjugate exhibiting antitumor activity. British Polym J, 23, 221-228.

60. Ohya Y, Kobayashi H, Ouchi T. 1991. Design of poly( $\alpha$-malic acid)-5FU-saccharide conjugate exhibiting antitumor activity. Reactive Polymers, 15, 153-163.

61. Ouchi T, Fujino A, Tanaka K, Banda T. 1993. Synthesis and antitumor activity of conjugates of poly( $\alpha$-malic acid) and 5-fluorouracils bound via ester, amide or carbamoyl bonds. J Control Release, 12, 143-153.

62. Ohya Y, Hirai K, Ouchi T. 1992. Synthesis and cytotoxic activity of doxorubicin bound to poly( $\alpha$-malic acid) via ester or amide bonds. Makromol Chem, 193, 18811887. 
63. Ohya Y, Hirai K, Ouchi T. 1992. Cell specific anticancer drug delivery using poly $(\alpha-$ malic acid)/saccharide conjugate. Proceed Intern Symp Control Rel Bioact Mater, 19, 68-69.

64. Ichinose K, Nakata K, Ishii N, Ohya Y, Ouchi T, Kanemastu T. 1998. Cell-typespecific augmentation of the tumoricidal activity of polymeric adriamycin combined with galactosamine. Acta Medica Nagasakiensia, 43(1-2), 12-15.

65. Bakr MA, Islam MdA, Sarker MAW, Islam MA, Hamed M. 2000. Malic acid-propane 1,2-diol copolyester as an enteric coating material. J Polym Mater, 19, 87-92.

66. Bakr MA, Islam MA, Karim MA, Sadik G, Biswas MHU. 2002. Drug delivery profile of malic acid-phthalic acid-propane 1,2-diol copolyester. J Polym Mater, 17, 467-472.

67. Bakr MA, Khatum S, Islam MA. 2003. In vitro drug release profile of malic acidbutane 1,4-diol copolyester. J Polym Mater, 20, 337-342.

68. He B, Chan-Park M. 2005. Synthesis and characterization of functionalizable and photopatternable poly( $\varepsilon$-caprolactone-co-RS- $\beta$-malic acid). Macromolecules, 38, 8227 8234.

69. He B, Wan E, Chan-Park M. 2006. Synthesis and degradation of biodegradable photocross-linked poly( $\alpha, \beta$-malic acid)-based hydrogel. Chem Mat, 18, 3946-3955.

70. He B, Zeng J, Nie Y, Ji L, Wang R, Li Yuan, Wu Y, Li L, Wang G, Luo Z, Gu Z. 2009. In situ gelation of supramolecular hydrogel for anti-tumor drug delivery. Macromol Biosci, 9, 1169-1175.

71. Poon YF, Cao Y, Zhu Y, Judeh ZMA, Chan-Park MB. 2009. Addition of b-malic acidcontaining poly(ethylene glycol) dimethacrylate to form biodegradable and biocompatible hydrogels. Biomacromolecules, 10, 2043-2052.

72. He B, Bei J, Wang S. 2003. Synthesis and characterization of functionalized biodegradable copolymer: poly(L-lactide-co-RS- $\beta$-malic acid). Polymer, 44, 989-994.

73. He B, Bei J, Wang S. 2003. Morphology and degradation of biodegradable poly(Llactide-co-RS-ß-malic acid). Polym Adv Technol, 14, 645-652.

74. He B, Wan Y, Bei J, Wang S. 2004. Synthesis and cell affinity of functionalized poly(L-lactide-co- $\beta$-malic acid) with high molecular weight. Biomaterials, 25, 52395247.

75. He B, Poon YF, Feng J, Chan-Park M. 2008. Synthesis and characterization of functionalized biodegradable poly(DL-lactide-co-RS- $\beta$-malic acid). J Biomed Mat Res Part A, 87A(1), 254-263. 
76. Lai KL, He B, Gu ZW. 2008. Preparation and cell compatibility of functionalized biodegradable poly(DL-lactide-co-RS- $\beta$-malic acid). Chinese J Polym Sci, 26(2), 177 186.

77. Liu Y, Wang W, Wang J, Wang Y, Yuan Z, Tang S, liu M, Tang H. 2010. Blood compatibility evaluation of poly(D,L-lactide-co-beta-malic acid) modified with GRGDS sequence. Colloids and Surfaces B: Biointerfaces, 75, 370-376.

78. Wang W, Liu Y, Wang J, Jia X, Wang L, Yuan Z, Tang S, Liu M, Tang H, Yu Y. 2009. A novel copolymer poly(lactide-co- $\beta$-malic acid) with extended carboxyl arms offering better cell affinity and hemacompatibility for blood vessel engineering. Tissue Engineering: Part A, 15(1), 65-73.

79. Stolnik S, Davies MC, Illum L, Davis SS, Boustta M, Vert M. 1994. The preparation of sub-200 nm biodegradable colloidal particles from poly( $\beta$-malic acid-co-benzyl malate) copolymers and their surface modification with Poloxamer and Poloxamine surfactants. J Control Release, 30, 57-67.

80. Stolnik S, Garnett MC, Davies MC, Illum L, Boustta M, Vert M, Davis SS. 1995. The colloidal properties of surfactant-free biodegradable nanospheres from poly( $\beta$-malic acid-co-benzyl malate)s and poly(lactic acid-co-glycolide).Colloids and Surfaces A: Physicochemical and Engineering Aspects, 97, 235-245.

81. Stolnik S, Garnett MC, Davies MC, Illum L, Davis SS, Boustta M, Vert M. 1996. Nanospheres prepared from poly( $\beta$-malic acid) benzyl ester copolymers: evidence for their in vitro degradation. J Mat Sci: Mat in Medicine, 7, 161-166.

82. Osanai S, Nakamura K. 2000. Effect of complexation between liposome and poly(malic acid) on aggregation and leakage behaviour. Biomaterials, 21, 867-876.

83. Nottelet B, Di Tommaso C, Mondon K, Gurny R, Möller M. 2010. Fully biodegradable polymeric micelles based on hydrophobic- and hydrophilicfunctionalized poly(lactide) block copolymers. J Polym Sci: Part A: Polym Chem, 48, 3244-3254.

84. Wang L, Jia X, Liu X, Yuan Z, Huang J. 2006. Synthesis and characterization of a functional amphiphilic diblock copolymer: MePEG- $b$-poly(DL-lactide-co-RS- $\beta$-malic acid). Colloid Polym Sci, 285, 273-281.

85. Wang L, Neoh KG, Kang ET, Shuter B, Wang SC. 2010. Biodegradable magneticfluorescent magnetite/poly(DL-lactic acid-co- $\alpha, \beta$-malic acid) composite nanoparticles for stem cell labeling. Biomaterials, 31, 3502-3511. 
86. Ying JY, Erathodiyil N, Lin AWH, Selvin ST. 2011. Polymer coated magnetic particles. PCT Int Appl. WO 2011053252 (A1).

87. Bouclier C, Moine L, Hillaireau H, Marsaud V, Connault E, Opolon P, Couvreur P, Fattal E, Renoir JM. 2008. Physicochemical characteristics and preliminary in vivo biological evaluation of nanocapsules loaded with siRNA targeting estrogen receptor alpha. Biomacromolecules, 9, 2881-2890.

88. Yang X, Grailer JJ, Pilla S, Steeber DA, Gong S. 2010. Tumor-targeting, pHresponsive, and stable unimolecular micelles as drug nanocarriers for targeted cancer therapy. Bioconjugate Chem, 21, 496-504.

89. Zhao Z, He M, Yin L, Bao J, Shi L, Wang B, Tang C, Yin C. 2009. Biodegradable nanoparticles based on linoleic acid and poly( $\beta$-malic acid) double grafted chitosan derivatives as carriers of anticancer drugs. Biomacromolecules, 10, 565-572.

90. Wang B, He C, Tang C, Yin C. 2011. Effects of hydrophobic and hydrophilic modifications on gene delivery of amphiphilic chitosan based nanocarriers. Biomaterials, 32, 4630-4638.

91. Wang J, Ni C, Zhang Y, Zhang M, Li W, Yao B, Zhang L. 2014. Preparation and pH controlled release of polyelectrolyte complex of poly(L-malic acid-co-D,L-lactic acid) and chitosan. Colloids and Surfaces B: Biointerfaces, 115, 275-279.

92. Pounder RJ, Willcock H, Ieong NS, O’Reilly RK, Dove AP. 2011. Stereocoplexation in novel degradable amphiphilic block copolymer micelles of poly(ethylene oxide) and poly(benzyl $\alpha$-malate). Soft Matter, 7, 10987-10993.

93. Shen R, Du P, Mu B, Liu P. 2011. Biocompatible and biodegradable polymeric nanocapsules from poly $(\alpha, \beta$-malic acid)-grafted nano-silica templates. Designed Monomers and Polymers, 14, 39-45.

94. Schott MA, Domurado M, Leclercq L, Barbaud C, Domurado D. 2013. Biomacromolecules, 14, 1936-1944.

95. Bizzarri R, Chiellini F, Solaro R, Chiellini E, Cammas-Marion S, Guérin Ph. 2002. Synthesis and characterization of new malolactonate polymers and copolymers for biomedical applications. Macromolecules, 35, 1215-1223.

96. Cammas S, Béar MM, Harada A, Guérin Ph, Kataoka K. 2000 b. New macromolecular micelles based on degradable amphiphilic block copolymers. Macromol Chem Phys, 201(3), 355-364.

97. Huang ZW, Laurent V, Chétouani , Ljubimova JY, Holler E, Benvegnu T, Loyer P, Cammas-Marion S. 2012. New functional and bio-degradable nanoparticles based on 
poly(malic acid) derivates for site-specific anti-cancer drug delivery. Int J Pharm, 243, 84-92.

98. Loyer P, Bedhouche W, Huang ZW, Cammas-Marion S. 2013. Degradable and biocompatible nanoparticles decorated with cyclic RGD peptide for efficient delivery to hepatoma cells in vitro. Int J Pharm, 454, 727-737.

99. Martinez-Barbosa ME, Cammas S, Appel M, Ponchel G. 2004. Investigation of the degradation mechanisms of poly(malic acid) esters in vitro and their related cytotoxicities on J774 macrophages. Biomacromolecules, 5, 137-143.

100. Reddy LH, Couvreur P. 2011. Nanotechnology for therapy and imaging of liver diseases. J Hepatology, 55(6), 1461-1466.

101. Le Droumaguet B, Nicolas J, Brambilla D, Mura S, Maksimenko A, De Kimpe L, Salvati E, Zona C, Airoldi C, Canovi M, Gobbi M, Noiray M, La Ferla B, Nicotra F, Scheper W, Flores O, Masserini M, Andrieux K, Couvreur P. 2012. Versatile and efficient targeting using a single nanoparticulate platform: application to cancer and Alzheimer's disease. ACS Nano, 6, 5866-5879.

102. Patil YB, Toti US, Khdair A, Ma L, Panyam J. 2009. Single-step surface functionalization of polymeric nanoparticles for targeted drug delivery. Biomaterials, 30, 859-866.

103. Kim SY, Cho SH, Lee YM, Chu LY. 2007. Biotin-conjugated block copolymeric nanoparticles as tumor-targeted drug delivery systems. Macromol Res, 15, 646-655.

104. Yang W, Cheng Y, Xu T, Wang X, Wen LP. 2009. Targeting cancer cells with biotindendrimer conjugates. Eur J Med Chem, 44, 862-868. 